\title{
Immunity to the respiratory pathogen Bordetella pertussis
}

\author{
R Higgs $^{1}$, SC Higgins ${ }^{2}$, PJ Ross ${ }^{2}$ and KHG Mills ${ }^{1,2}$
}

Bordetella pertussis causes whooping cough, a severe respiratory tract infection in infants and children, and also infects adults. Studies in murine models have shown that innate immune mechanisms involving dendritic cells, macrophages, neutrophils, natural killer cells, and antimicrobial peptides help to control the infection, while complete bacterial clearance requires cellular immunity mediated by T-helper type 1 (Th1) and Th17 cells. Whole cell pertussis vaccines (wP) are effective, but reactogenic, and have been replaced in most developed countries by acellular pertussis vaccines (aP). However, the incidence of pertussis is still high in many vaccinated populations; this may reflect sub-optimal, waning, or escape from immunity induced by current aP. Protective immunity generated by wP appears to be mediated largely by Th1 cells, whereas less efficacious alum-adjuvanted aP induce strong antibody Th2 and Th17 responses. New generation aP that induce Th1 rather than Th2 responses are required to improve vaccine efficacy and prevent further spread of $B$. pertussis.

\section{INTRODUCTION}

Bordetella pertussis, the causative agent of pertussis or whooping cough is a Gram-negative, aerobic coccobacillus of the genus Bordetella that also includes Bordetella parapertussis, which can infect humans and Bordetella bronchiseptica, which mainly infects animals such as dogs, cats, and pigs. B. pertussis still accounts for significant morbidity and mortality in children worldwide. ${ }^{1,2}$ The World Health Organization estimated that there were 16 million cases of pertussis worldwide in 2008 and that 195,000 children died from the disease, mostly in developing countries. ${ }^{1}$ Whole-cell pertussis vaccines (wP) were introduced in the 1950s, but because of their reactogenicity, were replaced in most developed countries over 10 years ago by safer acellular pertussis vaccines (aP), comprising two or more protective antigens. Although an extensive course of immunization with aP provides a good level of protection against severe pertussis in children, the incidence of pertussis has increased in many developed countries, particularly in adolescents and adults. Furthermore, 10 infant deaths from over 7,200 cases of pertussis were reported in California in 2010, which was the highest number of cases reported since 1947, surpassing a recent peak of 3,182 cases in 2005. ${ }^{3}$ The epidemic was not confined to California, with similar reports from Michigan, Ohio, and Oklahoma and in other countries, including Australia and Ireland. ${ }^{4-6}$ This resurgence of pertussis may, in part, reflect improved detection methods, but may also be associated with escape from immunity owing to antigen variation or poor or short-lived adaptive immunity induced by the aP when compared with the $\mathrm{wP}$ that they replaced.

Although no single correlate of immunity has emerged, considerable progress has been made in our understanding of the complex mechanisms of protective immunity to $B$. pertussis. Studies in humans have been complemented by more revealing experiments in murine respiratory challenge models. Although not perfect for replicating certain aspects of the human disease, notably the cough, the mouse models have provided very useful tools to dissect the role performed by different arms of the innate and adaptive immune response during the bacterial clearance and have highlighted potential approaches to improve vaccine efficacy in humans. One issue that has complicated our understanding of immunity to $B$. pertussis and the development of effective subunit or acellular vaccines is that $B$. pertussis produces a number of toxins, including pertussis toxin (PT), tracheal cytotoxin (TCT), adenylate cyclase toxin (ACT), heat-labile toxin, and endotoxin or lipopolysaccharide (LPS), and a range of other critical receptor-binding virulence factors, including filamentous hemagglutinin (FHA), pertactin (PRN), and fimbriae, all of which are known to contribute to pathogenesis and many of which are antigenic targets for antibodies and $\mathrm{T}$ cells. In addition, many of these toxins and virulence factors,

${ }^{1}$ Immunology Research Centre, Trinity Biomedical Sciences Institute, School of Biochemistry and Immunology, Dublin, Ireland. ${ }^{2}$ Immune Regulation Research Group, Trinity Biomedical Sciences Institute, School of Biochemistry and Immunology, Dublin, Ireland. Correspondence: KHG Mills (kingston.mills@tcd.ie) 
as well as mediating adherence to ciliated epithelial cells, macrophages, and neutrophils, also promote bacterial survival in the respiratory tract by subverting immune responses of the host. Furthermore, as well as replicating extracellularly on respiratory epithelial cells, B. pertussis can also be taken up and survive in macrophages, suggesting that cell-mediated as well as humoral immunity are required for clearance of the bacteria from the respiratory tract.

Studies on cellular immunity to $B$. pertussis have shown that recovery from whooping cough in children is associated with the induction of interferon (IFN)- $\gamma$-secreting T helper type 1 (Th1) cells. ${ }^{7,8}$ Complementary studies in mice have shown that IFN- $\gamma$ is required for the control of $B$. pertussis infection in the respiratory tract; mice lacking this cytokine or its receptor develop disseminating and lethal infection. ${ }^{9,10}$ Furthermore, experiments involving cell depletion or adoptive transfer have provided convincing evidence of a role for Th1 cells in clearance of a primary infection or following immunization with $\mathrm{wP}^{9,}, 11-13$ By contrast, immunization of mice with aP induces Th2-type responses, which promote humoral immunity, but do not appear to be as effective as Th1 cells in clearance of B. pertussis from the respiratory tract. Clinical studies concur with these findings and have demonstrated selective induction of Th1 cells in children following immunization with wP but strong antibody and Th2 dominated responses following immunization with aP. ${ }^{14,15}$ Thus, the failure of alum-adjuvanted aP to induce Th1 responses, and hence IFN- $\gamma$ secretion, may be one explanation for the increasing incidence of pertussis in populations using aP.

\section{LOCAL IMMUNITYTO B. PERTUSSIS INTHE RESPIRATORYTRACT}

$B$. pertussis binds to the cilia of the trachea, bronchi, and bronchioles and intracellular bacteria have been detected in the ciliated epithelial cells and macrophages from the lungs of infected infants/children and mice. ${ }^{16-19}$ Resident and infiltrating macrophages and immature dendritic cells (DCs) are the first cells of the innate immune system to sense and respond to B. pertussis infection (Figure 1). Studies in the murine respiratory challenge model have shown that infection of naive mice with $B$. pertussis is accompanied by an inflammatory infiltrate in the lungs, with an influx of DCs, macrophages, neutrophils, and lymphocytes. ${ }^{20}$ An initial infiltrate of DCs and macrophages is followed by an influx of neutrophils, then natural killer (NK) cells, and finally $\alpha \beta \mathrm{T}$ cells, predominantly though not exclusively CD ${ }^{+}$T cells. ${ }^{12,13,20}$ Secretory immunoglobulin A (IgA) and $\operatorname{IgG}$ (which transudates from the serum) is also detected in the lungs of mice; however, serum IgG is only detectable when the bacteria are almost cleared from the respiratory tract. ${ }^{11}$ These findings provide indirect evidence that innate cells, including macrophages and neutrophils, activated by cytokines secreted by $\mathrm{NK}$ cells and $\mathrm{CD} 4^{+} \mathrm{T}$ cells, help to clear a primary infection with B. pertussis. Although B. pertussis-specific antibodies and $T$ cells confer adaptive immunity induced by previous infection or vaccination, there is rapid cell recruitment to the lungs following re-challenge of immune mice, suggesting

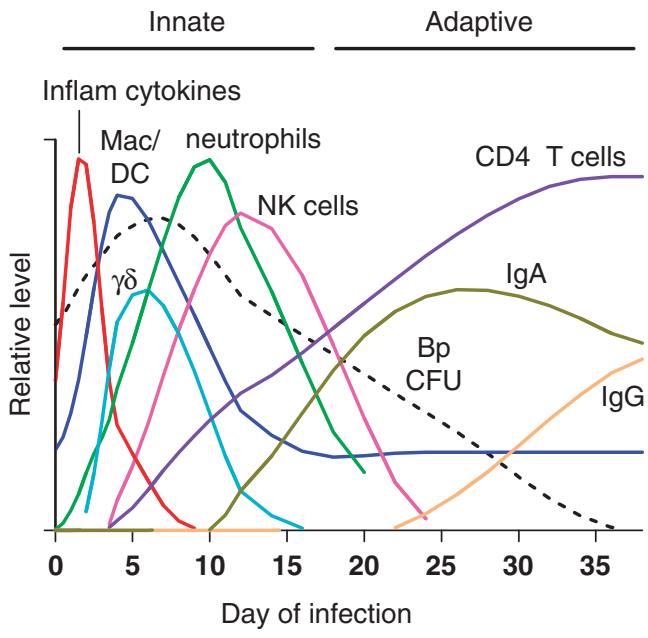

Figure 1 Kinetics of cell recruitment to the lungs and immune responses following infection with Bordetella pertussis. Hypothetical curves representing relative numbers of immune cells recruited to the lungs of mice following primary infection with $B$. pertussis. CD4T cells: recruitment of $C D 4^{+} T$ cells to the lungs and response of the lung $T$ cells to $B$. pertussis antigens. Immunoglobulin (Ig) G: anti-B. pertussis IgG in serum. IgA: anti-B. pertussis IgA in lungs. Bp CFU: B. pertussis bacterial burden in the lungs. DC, dendritic cells; Mac, macrophage; NK, natural killer.

that infiltrating cells may also contribute to protection (at least in mice) in the immune host.

\section{INNATE IMMUNITY TO B. PERTUSSIS Macrophages}

$B$. pertussis have been found in pulmonary alveolar macrophages from infants and children with confirmed $B$. pertussis pneumonia $^{18}$ and in alveolar macrophages of HIV-infected children. ${ }^{21}$ Animal models of $B$. pertussis infection and in vitro studies using human monocytes have revealed that $B$. pertussis can enter, survive, and persist in macrophages, ${ }_{16}^{16,19,22,23}$ suggesting that these cells may provide an intracellular niche to extend infection, and increase the opportunity to spread to new hosts. Shortly after phagocytosis, a high proportion of ingested bacteria are destroyed within acidic compartments, but a proportion of the bacteria can evade destruction and can replicate in macrophages by residing in the non-acidic compartments. ${ }^{24}$ As well as providing an intracellular niche for survival, macrophages have also been shown to contribute to protective immunity; depletion of resident airway macrophages enhanced infection by $B$. pertussis. ${ }^{16}$ The killing of $B$. pertussis by macrophages is enhanced by IFN- $\gamma^{25}$ and interleukin (IL)-17. ${ }^{26}$ Nitric oxide (NO) production by macrophages is induced by IFN- $\gamma$, but not by IL- $17,{ }^{26}$ which is consistent with the demonstration that macrophages utilize both NO-dependent and independent mechanisms to kill B. pertussis. ${ }^{25}$ Collectively these findings suggest that the macrophages can harbor B. pertussis intracellularly and as macrophages can be activated to kill intracellular $B$. pertussis by T-cell derived cytokines, such as IFN- $\gamma^{25}$ and IL-17, ${ }^{26}$ this provides indirect evidence of the importance of Th1 and Th17 cells in the clearance of intracellular bacteria. 


\section{DCs}

The key function of DCs is to present antigens to T cells and provide a source of innate cytokines that promote differentiation of naive T cells. Resident and infiltrating immature DC in the respiratory tract sense pathogen-associated molecular patterns and virulence factors from $B$. pertussis. This recognition promotes strong proinflammatory signals that are crucial in triggering early cytokine and chemokine production and accompanying leucocyte infiltration, followed by activation of host T-cell responses to infection. The binding of LPS to Tolllike receptor 4 (TLR4) on DC promotes their maturation and the secretion of IL-12 and IFN- $\gamma,{ }^{27,28}$ which drives the induction of Th1 cells (Figure 2). The DC subtypes involved appear to be either $\mathrm{CD} 11 \mathrm{c}^{+} \mathrm{CD} 8 \alpha^{+}$or $\mathrm{CD} 11 \mathrm{c}^{+} \mathrm{CD} 8 \alpha^{+} \mathrm{CD} 103^{+} \mathrm{DC}$, as these are detected in cervical lymph nodes soon after infection with $B$. pertussis, and migrate to the lung where they produce IFN $-\gamma$, which help to promote the induction of Th1 cells. Evidence of the importance of these DC subtypes was provided by experiments in mice that showed that depletion of $\mathrm{CD} 8 \alpha^{+}$cells or blocking CD103 early in infection attenuated Th1 responses in the lungs and significantly reduced bacterial clearance, whereas transfer of FLT3 (fms-like tyrosine kinase receptor 3) ligandexpanded $\mathrm{CD} 11 \mathrm{c}^{+} \mathrm{CD} 8 \alpha^{+}$DC enhanced bacterial clearance. ${ }^{12}$ These studies provide evidence that these DC subtypes have an important role in immunity to $B$. pertussis by inducing Th1 cells, which help to mediate bacterial clearance.

DC activated with ACT from $B$. pertussis also promote the induction of $B$. pertussis-specific Th17 cells, which function with Th1 cells to clear bacteria from the respiratory tract of infected mice $^{29}$ (Figure 2). Stimulation of DC with ACT promotes activation of caspase-1 and the NOD-like receptor (NLR) family, pyrin domain-containing 3 (NLRP3) inflammasome required for processing of the pro-IL- $1 \beta$ to its mature form and IL- $1 \beta$, together with IL-23, promote the induction of $B$. pertussisspecific Th17 cells. ${ }^{29}$ Similarly, infection of monocyte-derived human DC with $B$. pertussis induces IL-1 and IL-23 required for expansion of human Th17 cells. ${ }^{30}$

The $B$. pertussis virulence factors ACT and FHA promote antiinflammatory responses, including IL-10 production by DC, leading to the generation of IL-10-producing regulatory $\mathrm{T}$ (Treg) cells. ${ }^{27,31}$ Furthermore, although LPS promotes proinflammatory responses, it also stimulates IL-10 production from DC, ${ }^{27}$ which can drive the induction of Treg cells. These Treg cells have a putative protective role as the absence of IL-10-secreting $\mathrm{T}$ cells resulted in increased mortality from overwhelming inflammation in the lungs caused by $B$. pertussis infection..$^{27,32}$

\section{Neutrophils}

B. pertussis is taken up and can survive within subcellular structures in neutrophils that undergo lysosomal maturation. ${ }^{33}$ Unlike macrophages, however, neutrophils are unlikely intracellular reservoirs for B. pertussis due to their short half-life, but they may have a role in killing phagocytosed bacteria. Neutrophils infiltrate the lungs of mice around 5 days after respiratory challenge with $B$. pertussis and peak around day $10-14 .{ }^{20,34}$ Innate IL-6 is required for macrophage inflammatory protein 2 production and associated neutrophil recruitment as well as induction of Th1 and Th17 responses to B. pertussis. ${ }^{35} \mathrm{PT}$ was shown to modulate the early immune response to $B$. pertussis by delaying the early infiltration of neutrophils. ${ }^{36}$ Similarly, ACT can inhibit neutrophil function by decreasing phagocytosis, superoxide generation, and inhibiting chemotaxis. ${ }^{37}$ However, this does not appear to impact on protective immunity to B. pertussis; although B. bronchiseptica infection of neutrophildeficient mice has a lethal outcome, neutrophils do not appear to have a critical role in clearing $B$. pertussis infection in naive mice. ${ }^{36,38}$ Nevertheless, neutrophils appear to be important in controlling infection in immune mice, possibly through antibody-mediated uptake and intracellular killing. ${ }^{36}$

\section{NK cells}

NK cells have a well-documented role in killing virally-infected cells, but also function in immunity to certain bacterial infections, including B. pertussis. Following B. pertussis infection of mice, NK cells provide the initial source of IFN $\gamma$, which is essential for containing the bacteria within the respiratory tract, ${ }^{13}$ and promoting Th1 responses that mediate bacterial clearance. ${ }^{9,10}$ Evidence of a protective role for NK cells was provided by the demonstration that $B$. pertussis infection of T-cell-deficient mice, though persistent, is confined to the lungs, ${ }^{11}$ whereas depletion of NK cells resulted in dissemination of the bacteria to the liver. ${ }^{13}$ Depletion of NK cells also resulted in a reduced Th1 and an elevated Th2 response, highlighting a role for NK cells in regulating the development of T-cell responses during infection. ${ }^{13}$

\section{Antimicrobial peptides}

A range of host defence proteins are secreted by the airway epithelium and innate immune cells, either constitutively or in response to bacterial infection. ${ }^{39}$ These include large proteins, such as lysozyme, lactoferrin, and secretory leukoproteinase inhibitor, and also the smaller antimicrobial peptides (AMPs), such as cathelicidin (LL-37) and the defensins. Variable susceptibility of $B$. pertussis to AMPs in vitro was demonstrated by radial diffusion assay, with AMPs of the cecropin family found to be the most effective, whereas $\alpha$-defensin and magainin AMPs were less potent. ${ }^{40}$ However, later studies revealed that $\beta$-defensins have strong antimicrobial activity against Bordetella species, such as canine $\beta$-defensin CBD103 and porcine $\beta$-defensin- 1 (pBD-1), which is a homologue of human $\beta$-defensin-2. ${ }^{41,42}$ Expression of pBD-1 in the upper respiratory tract of piglets ( $>4$ weeks of age) correlated with resistance to respiratory infection by $B$. pertussis, whereas newborn piglets, which lack pBD-1 expression, are susceptible to infection but are protected following in vivo treatment with recombinant $\mathrm{pBD}-1 .{ }^{41}$ By contrast, B. parapertussis is resistant to killing by $\mathrm{pBD}-1$ in vitro, and consequently $B$. parapertussis challenge in the same porcine model resulted in more severe disease. ${ }^{43}$ Taken together, these studies suggest that $\beta$-defensin AMPs are selectively protective and promote resistance to $B$. pertussis infection. As an evasion strategy, Bordetella species can inhibit nuclear factor $\mathrm{\kappa B}$ activation through the type III secretion system (TTSS), thus blocking the expression of defensins, such as tracheal AMP, and promoting 


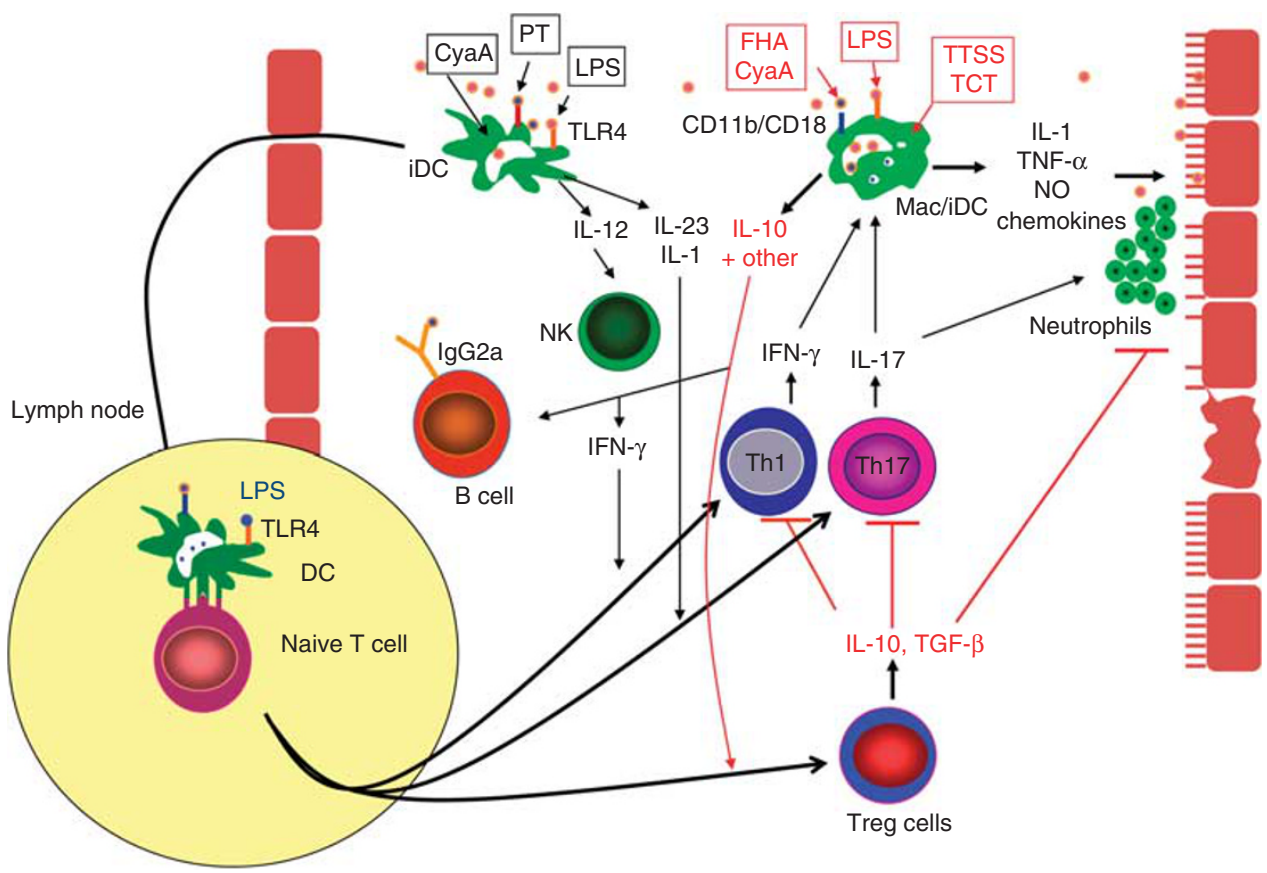

Figure 2 Immunity to Bordetella pertussis in a naive host: evidence from the murine respiratory challenge model. When $B$. pertussis enters the respiratory tract, the bacteria bind to ciliated epithelial cells, but are also recognized and taken up by resident or infiltrating cells of the innate immune systems, such as macrophages (Mac) and immature dendritic cells (iDC). DC process and present bacterial antigens to T cells. The production of interleukin (IL)-12 by innate cells results in polarization of the T-cell response to the Thelper type 1 (Th1) subtype, and IL-1 $\beta$ and IL-23 drive the differentiation of Th17 cells. However, in early infection the local T-cell responses are suppressed by innate cells that secrete IL-10 in response to filamentous hemagglutinin (FHA), adenylate cyclase toxin (ACT), or type III secretion system (TTSS) and by the consequent regulatory T (Treg) cells. Nitric oxide (NO) and the pro-inflammatory cytokines, IL-1 and tumor necrosis factor (TNF)- $\alpha$ are induced by bacterial toxins, especially lipopolysaccharide (LPS), tracheal cytotoxin (TCT), ACT, and pertussis toxin (PT), and as well as contributing to bacterial elimination, also mediate local lung pathology and are responsible for many of the systemic and neurological consequences of the infection. Interferon (IFN)- $\gamma$ secreted early in infection by DC and natural killer (NK) cells, and later in infection by Th1 cells, stimulates recruitment and activation of macrophages and neutrophils and provides help for B cells to secrete opsonizing and complement-fixing antibody (immunoglobulin (Ig) G2a in the mouse). IL-17 secreted by Th17 cells promotes macrophage inflammatory protein 2 production and neutrophil recruitment and activation. Opsonized or non-opsonized bacteria are taken up by neutrophils and macrophages, which are killed by NO or reactive oxygen intermediates. Black arrows represent inflammatory/effector immune responses and red arrows represent anti-inflammatory and immunosuppressive responses. TGF, transforming-growth factor; TLR4, Toll-like receptor 4 .

survival and colonisation. ${ }^{44}$ The induction of $\beta$-defensin- 2 can also be promoted by IL-17 in primary human airway epithelial cells, ${ }^{45}$ and although this is a distinct possibility with respect to the Th17 response to B. pertussis infection, to our knowledge it has yet to be described in the literature.

\section{Complement}

The Bordetella resistance to killing A (BrkA) protein confers $B$. pertussis with a degree of resistance to classical complementdependent killing. ${ }^{38,46}$ BrkA-dependent resistance occurs through the inhibition of neutrophil-mediated phagocytosis by interfering with the deposition of complement components onto the bacterial surface. ${ }^{47}$ However, susceptibility to complement remains highly variable. Although a mutant strain lacking BrkA was efficiently killed by sera from individuals with previous exposure to $B$. pertussis, partial killing of the wild-type strain was also observed and correlated with the presence of complement-fixing IgG3 antibodies. ${ }^{48}$ Furthermore, the specific growth phase of the bacteria, but not differential antigenic expression, has a role in determining susceptibility to complement. ${ }^{49,50}$ Expression of $\mathrm{O}$ antigen, for example, does not seem to be essential for resistance to serum in B. pertussis, unlike in other Bordetella strains. ${ }^{50,51}$ Inhibition of the classical complement pathway by $B$. pertussis is also achieved through other mechanisms, such as the recruitment of $\mathrm{C} 1$ esterase inhibitor $(\mathrm{C} 1 \mathrm{INH})$ and $\mathrm{C} 4 \mathrm{~b}$-binding protein $(\mathrm{C} 4 \mathrm{BP})$, which interfere with the function of $\mathrm{C} 1$ and $\mathrm{C} 4 \mathrm{~b}$, respectively. ${ }^{52,53}$ Finally, $B$. pertussis does not seem to be susceptible to the alternative or mannose-binding lectin pathways, as factor-B-depleted serum retained the ability to kill $B$. pertussis, unlike serum depleted of antibody. ${ }^{54}$ Indeed, clinical isolates of $B$. pertussis bind the alternative pathway inhibitor factor $\mathrm{H}$ in human serum, which retains its activity and leads to cleavage of $\mathrm{C} 3 \mathrm{~b}$ and protection from the alternative complement pathway. ${ }^{55}$

\section{HUMORAL IMMUNITY}

Infection of mice and humans with B. pertussis induces IgG and IgA; secretory IgA is detectable in mucosal secretions before detection of IgG in the serum, ${ }^{11}$ suggesting that it may be important in the control of B. pertussis infection. ${ }^{56} \mathrm{~B}$. pertussisspecific IgG and IgA can also be acquired by human newborns via colostrums and placental transfer, and there is some evidence 
that these can be protective. ${ }^{57}$ Although parentally delivered pertussis vaccines confer protection, they do not induce secretory IgA, although it is possible that rapid induction of IgA after challenge may contribute to bacterial clearance. By contrast, oral or nasally delivered pertussis antigens formulated with mucosal adjuvants do induce IgA in mice, but do not confer higher levels of protection than the equivalent parenterally delivered vaccines (Reviewed in Mills ${ }^{58}$ ). It is possible that the nasally delivered attenuated $B$. pertusis vaccine BPZE1, which is highly protective in mice, ${ }^{59}$ may have the advantage of inducing local as well as circulating IgG.

\section{Antibody in humans}

Passive immunization with antisera against $B$. pertussis has been shown to reduce the severity of disease in infected individuals, providing direct evidence of the protective role for antibodies in humans. ${ }^{60}$ Furthermore, the results of phase III clinical trials of pertussis vaccine carried out in the 1990s reported that aP that included PT and FHA, with or without PRN and fimbrae, generated relatively high levels of antibodies against the immunizing antigens. ${ }^{61-65}$ However, these studies did not provide definitive evidence of a role for antibodies in protection against B. pertussis. Indeed, some of the vaccines with rather low efficacy also elicited relatively strong antibody responses as detected by enzyme-linked immunosorbent assay. This anomaly may reflect an overdependence on enzyme-linked immunosorbent assay for antibody detection; antibody assays with increased functional relevance have been developed and may prove more useful. Furthermore, local antibodies (IgA and IgG) in the lung may be more relevant than those in the circulation. Finally, antiB. pertussis IgG concentrations in the serum give little information on the induction of immunological memory. Nevertheless, reports from household-exposure studies showed that the incidence of severe pertussis was lower in individuals with high serum antibody levels against PT and PRN. ${ }^{66,67}$ Furthermore, a study with a mono-component aP demonstrated that children were less likely to develop severe pertussis if they had higher levels of anti-PT antibodies. ${ }^{68}$ However, although antibody responses decline rapidly after immunization with most aP, ${ }^{66,69}$ many immunized children appear to remain protected against severe disease. ${ }^{70}$ These observations suggest that either memory $\mathrm{B}$ cells ${ }^{71}$ or more persistent $\mathrm{T}$-cell responses ${ }^{72}$ may mediate longterm adaptive immunity to $B$. pertussis.

\section{Antibody in mouse models}

B. pertussis-specific antibody responses are slow to develop in mice after $B$. pertussis respiratory challenge and antibody responses are not detected at significant levels until the bacteria are almost cleared after $4-6$ weeks, ${ }^{11}$ suggesting that antibodies do not have a major role in clearance of a primary infection with B. pertussis. By contrast, there is considerable evidence from passive and active immunization studies in murine models that antibodies are involved in vaccine-induced adaptive immunity to $B$. pertussis. ${ }^{73}$ It is possible that antibodies may function by (a) neutralizing bacterial toxins, (b) inhibiting binding of extracellular bacteria to epithelial cells in the respiratory tract, or (c) enhancing bacterial uptake for destruction by macrophages and neutrophils.

Immunization of mice with PT, FHA, PRN, fimbriae, or ACT induces antibody responses and confers varying levels of protection against respiratory or intracerebral challenge..$^{58}$ However, few of these studies provided formal evidence that antibodies conferred protection and some even demonstrated protection with minimal or undetectable antibody responses. ${ }^{72,74,75}$ Nevertheless, passive immunization experiments demonstrated that antibodies raised against distinct $B$. pertussis antigens can confer a level of protection. ${ }^{73}$ Antibodies against PT and PRN appear to be the most protective, whereas anti-FHA antibodies have limited efficacy, which is consistent with the conclusions from clinical studies. Furthermore, the combination of antibodies against different antigens was most protective, ${ }^{73}$ which is also consistent with clinical trials involving two-, three- or fivecomponent vaccines. ${ }^{61-65}$ Further evidence of a role for antibody in vaccine-induced immunity to $B$. pertussis in mice was provided by the demonstration that immunization with aP or wP failed to confer protective immunity in Ig-defective $\left(\mathrm{Ig}^{-/-}\right)$ mice. ${ }^{73}$ Naive $\mathrm{Ig}^{-/-}$mice also failed to clear B. pertussis and developed a chronic infection. ${ }^{73}$ However, $\mathrm{Ig}^{-1-}$ mice lack mature $B$ cells and fail to generate an effective T-cell response to $B$. pertussis. Intranasal immunization of $\mathrm{Ig}^{-1-}$ mice with inactivated B. pertussis resulted in partial protection, which was restored to full protection after transfer of $B$. pertussis-immune B cells. ${ }^{74}$ Therefore, B cells may protect against $B$. pertussis independently of antibody production, possibly through an organogenic role in mucosal immunity, ${ }^{76}$ or in antigen presentation to $\mathrm{T}$ cells.

\section{CELL-MEDIATED IMMUNITY}

Although the overwhelming focus of most studies on defining correlates of immunity to $B$. pertussis have focused on serum antibody responses, there is growing evidence that cellular immunity is required for effective clearance of a primary infection with B. pertussis from the respiratory tract and for immunity induced with wP. The discovery of Th1 and Th2 cells over a quarter of a century ago and the factors that promote their differentiation, notably IL-12 and IL-4 respectively, have provide a useful framework for understanding the role of humoral and cellular immunity to infection, with Th1 cells primarily involved in immunity to intracellular pathogens and Th2 to extracellular pathogens. ${ }^{77}$ Studies in immunized mice and humans have demonstrated that $\mathrm{wP}$ and $\mathrm{aP}$ induce distinct $\mathrm{Th} 1$ and $\mathrm{Th} 2$ subtypes, respectively. ${ }^{14,15}$ The more recent discovery of Treg cells, which prevent autoimmunity and immunopathology during infection, ${ }^{78}$ and IL-17-secreting Th17 cells, which are pathogenic in many inflammatory diseases but also promote neutrophil recruitment in immunity to fungi and extracellular bacteria, ${ }^{79}$ has added an extra layer of complexity to our understating of the role of $\mathrm{CD}^{+} \mathrm{T}$ cells in immunity to infection. In addition to Th1 cells, it appears that Treg and Th17 cells are induced by infection with $B$. pertussis and data are emerging that these cells may also have critical and distinct roles in the pathogenesis of B. pertussis infection. 


\section{T cells in humans}

Infection of children with $B$. pertussis results in the priming of $\mathrm{CD}^{+} \mathrm{T}$ cells specific for the $B$. pertussis antigens PT, FHA, and PRN. ${ }^{7,80}$ Furthermore, $T$ cells from the peripheral blood of infants with whooping cough or recovering from disease were found to secrete IFN- $\gamma$ and IL-2, but little or no IL-4 or IL-5. ${ }^{7}$ These results have been confirmed by other studies, ${ }^{8,81}$ and suggest that $B$. pertussis infection primes Th1 but not Th2 cells in children. Furthermore, T-cell clones specific for PT, FHA, or PRN derived from an adult donor who had suffered from whooping cough were shown to have a cytokine profile characteristic of Th1 cells. ${ }^{82} \mathrm{~T}$-cell proliferative responses to PT, FHA, or PRN were shown to inversely correlate with clinical pertussis. $^{83}$

B. pertussis-specific Th1 responses have also been detected in a proportion of "naive" children with no history of whooping cough, ${ }^{7}$ and in healthy adults with no record of vaccination, or history of pertussis. ${ }^{84}$ It is possible that natural exposure and the development of sub-clinical pertussis may help to maintain long-term immunity in previously infected or immunized individuals. Taken together, the data are consistent with a role for cellular responses mediated by Th1 cells in natural immunity to $B$. pertussis in humans. However, recent studies in humans have suggested that Th17 cells are also induced in response to B. pertussis, ${ }^{30}$ and studies in mice have demonstrated that these cells may also have a role in protective immunity. ${ }^{26,85}$ However, IL-23-driven Th17 cells are pathogenic in murine autoimmune diseases and IL17R or IL23R have been identified as possible susceptibility genes in certain autoimmune diseases in humans. ${ }^{86}$ Furthermore, polymorphisms in IL23R are associated with protection against pulmonary hypertension in systemic sclerosis. ${ }^{87}$ As leukocytosis and pulmonary hypertension is common in fatal cases of pertussis in young infants, ${ }^{18}$ it is possible Th17 cells may also contribute to pulmonary pathology during $B$. pertussis infection.

Immunization of children with $\mathrm{wP}$, like natural infection, induces $B$. pertussis-specific CD $4^{+} \mathrm{T}$ cells that secrete IFN$\gamma \cdot{ }^{14,15}$ Although one report concluded that aP also selectively induced Th1 cells, ${ }^{88}$ studies from several independent laboratories demonstrated that primary immunization with aP generated T cells with a Th2 or mixed Th1/Th2 cytokine profile. ${ }^{14,15,89}$ In addition, administration of a fourth or fifth booster immunization significantly enhanced Th2 responses and IgE production. ${ }^{90}$ Furthermore, the Th1 profile induced with wP was broadened to a mixed Th1/Th2 profile after boosting with aP. ${ }^{14}$ An examination of T-cell responses in children at extended intervals after immunization demonstrated persistence of the T-cell responses in a high proportion of individuals. ${ }^{14,91}$ However, injectionsite reactions, including redness and limb swelling, have been reported in children after a fifth dose of $\mathrm{aP}^{92}$ As Th2 responses are particularly pronounced after a booster vaccination with $\mathrm{aP}$, it is possible that the local reactions can be attributed to hypersensitivity mediated by Th2 cells.

\section{Effector T cells in murine models}

$\gamma \delta$ T cells are recruited to the lungs early after infection of mice with B. pertussis. ${ }^{20} \gamma \delta \mathrm{TCR}^{-/-}$mice have a lower B. pertussis bacterial load early in infection but increased lung pathology compared with wild-type mice; this study concluded that $\gamma \delta \mathrm{T}$ cells have a role in orchestrating early innate cell traffic to the respiratory tract. ${ }^{93}$ The development of an adaptive immune response following primary $B$. pertussis infection is relatively slow, with $\mathrm{CD} 4{ }^{+} \mathrm{T}$-cell responses detected in the lungs after about 3 weeks post infection, followed by detection in the draining lymph nodes and spleen. ${ }^{11,20}$ Antigen-specific CD4 ${ }^{+} \mathrm{T}$ cells from infected or convalescent mice secrete IFN- $\gamma$ and/or IL-17, suggesting that Th1 and Th17 cells are induced by infection with B. pertussis. ${ }^{11,29}$ Th1 cells differentiate from naive T cells in response to the inflammatory cytokine IL-12 secreted by innate immune cells in response to various $B$. pertussis virulence factors. ${ }^{94}$ B. pertussis-infected IFN- $\gamma^{-/-}$mice have a significantly impaired ability to clear the bacteria, ${ }^{10}$ and IFN- $\gamma \mathrm{R}^{-1-}$ mice can develop a lethal disseminated infection. ${ }^{9}$ IFN- $\gamma$ produced by Th1 cells activates NO production by macrophages, which help to eliminate the bacteria. ${ }^{25,95,96}$

Little or no Th2 cells are induced following primary infection of mice with $B$. pertussis mice. ${ }^{34}$ Furthermore, IL- $4^{-1-}$ mice clear $B$. pertussis infection at the same rate as wild-type mice. ${ }^{34}$ Interestingly, although IFN $-\gamma \mathrm{R}^{-1}$ mice lack Th1 responses, and Th2 cells do not develop in these mice, they can still clear the bacteria if they survive the initial infection, ${ }^{9}$ probably through the function of Th17 cells. These IL-17-producing CD $4^{+}$cells are induced during infection, ${ }^{29,30,97}$ driven by innate IL- 1 and IL-23, and are critical for successful clearance of $B$. pertussis ${ }^{29,35}$ via the recruitment of neutrophils and the activation of both macrophage- and neutrophil-mediated killing of B. pertussis. ${ }^{26,98}$ The induction of effective adaptive immunity against $B$. pertussis therefore requires both Th1 and Th17 cells.

The earliest studies on cellular immunity generated by immunization of mice showed that wP induced polarized Th1 responses, whereas aP primarily induced Th2 cells ${ }^{99,100}$ (Figure 3). Although aP do provide protection, the rate of clearance of $B$. pertussis is slower in aP- compared with wPimmunized mice and this appears to reflect the failure of aP to induce Th1 cells. ${ }^{99,101,102}$ Originally, the induction of Th2 cells and high levels of antibodies was thought to be the sole mechanism of aP-induced protection. ${ }^{100}$ However, IL- $4^{-1-}$ mice, which do not develop Th2 cells, are still protected by vaccination with aP (Ross and Mills, unpublished). Transfer of high-titre antibodies generated by infection or vaccination can passively transfer immunity to naive mice, ${ }^{73}$ demonstrating a protective role for high levels of circulating antibodies. ${ }^{74}$ However, recent results from this laboratory have identified a critical role for Th17 cells in aP-induced protection. ${ }^{103}$ We have shown that IL-1 induced by vaccination with aP promotes IL-17 production from Th17 cells, which increases neutrophil recruitment and the activation of bacterial killing (Ross and Mills, unpublished). We have also demonstrated that wP induces Ag-specific Th17 cells in immunized mice ${ }^{26}$ and found that these cells work in combination with Th1 cells to mediate bacterial clearance. The mechanism appears to involve the recruitment and activation of macrophages and neutrophils, which kill B. pertussis ${ }^{25,26}$ and reduce the bacterial burden in the respiratory tract. 


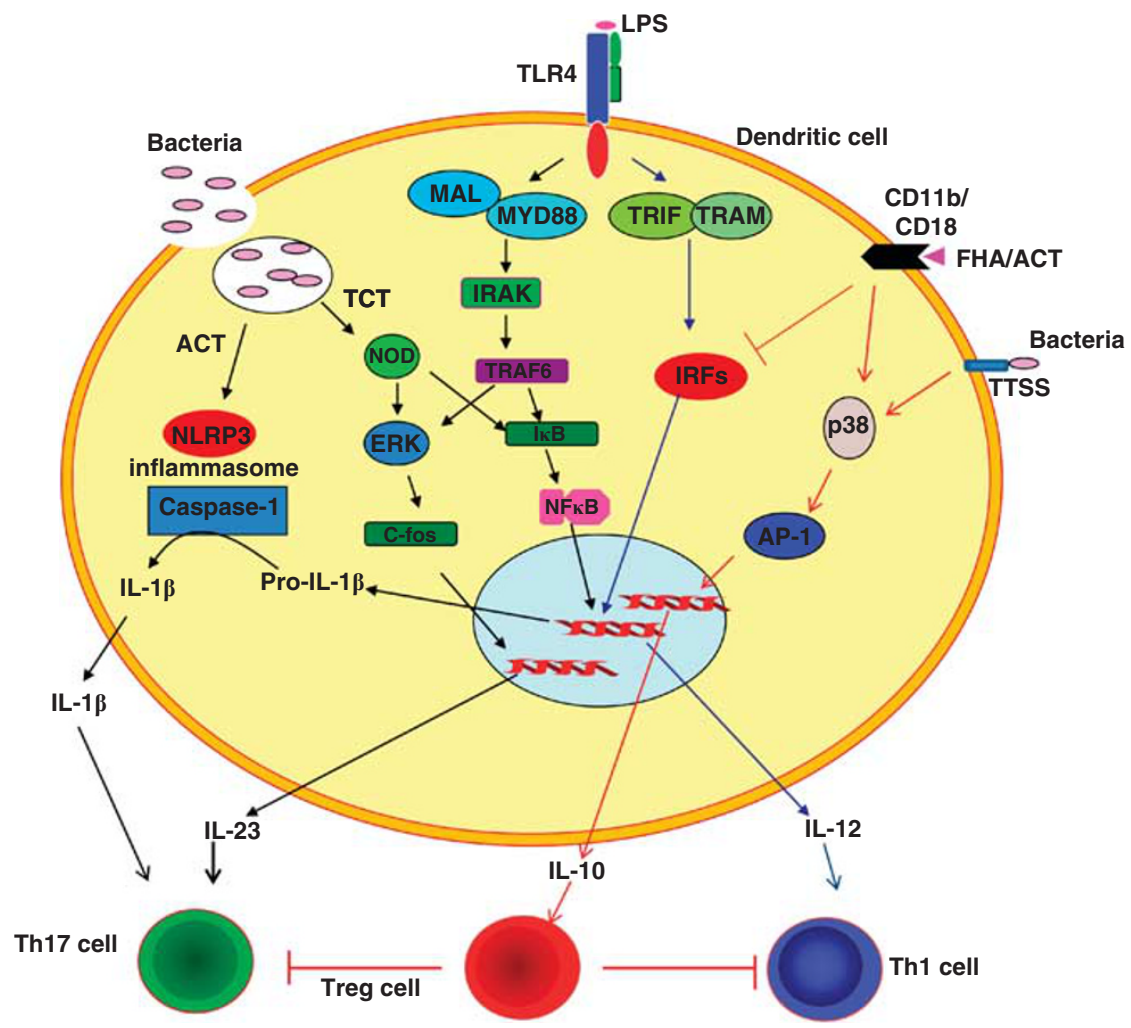

Figure 3 Dendritic cell activation by Bordetella pertussis leading to induction of effector Thelper type 1 (Th1) and Th17 cells and interleukin (IL)-10-producing regulatory T (Treg) cells. Lipopolysaccharide binding to Toll-like receptor 4 (TLR4) activates interferon regulatory factor (IRF) pathway leading to IL-12 production, ERK MAP (extracellular signal-regulated mitogen-activated protein) kinase leading to IL23 and nuclear factor $\kappa B(N F K B)$ leading to pro-IL1 $\beta$ production. Intracellular bacteria release nucleotide-binding and oligomerization domain (NOD)-like receptor (NLR) agonists, including tracheal cytotoxin (TCT) that activates NOD-1 and adenylate cyclase toxin (ACT) that activates caspase-1 and the NLRP3 inflammasome complex, which processes pro-IL-1 $\beta$ into mature IL-1 $\beta$. IL-12 promotes induction of Th1 cells, whereas IL-6, IL-1 $\beta$, and IL-23 promote induction and expansion of Th17 cells. Finally, filamentous hemagglutinin (FHA) or ACT binding to CD11b/CD18 activates p38 MAP kinase and suppresses IL-12 production, resulting in IL-10 production and the induction of Treg cells that suppress Th1 and Th17 cells. Black, blue, and red arrows represent pathways involved in inducing Th17, Th1, and Treg cells, respectively. AP-1, activator protein 1; MAL, MyD88 adapter like; MYD88, myeloid differentiation primary response gene (88); TRAF6, TNF receptor-associated factor 6; TRIF, TIR-domaincontaining adapter-inducing interferon- $\beta$; TRAM, TRIF-related adaptor molecule; TTSS, type III secretion system.

\section{Treg cells}

B. pertussis, like many other pathogens that cause persistent infections, has evolved mechanisms to subvert host protective immune responses and prolong their survival in the host and these include the induction of Treg cells. ${ }^{104,105}$ The B. pertussis virulence factors FHA and ACT promote IL-10 secretion and inhibit IL-12p70 production and maturation of DC and macrophages and thereby promote the induction of Treg cells. ${ }^{31,106,107}$ Although protective Th1 and Th17 responses can be detected both locally and systemically during infection, IL-10-secreting Tr1-type cells are also detectable at the site of infection and are induced simultaneously with $\mathrm{Th} 1$ cells. ${ }^{31} \mathrm{Tr} 1$ cells secrete high levels of IL-10, with low levels of IL-5 and IFN- $\gamma$ and no IL-4 and directly suppress inflammatory Th1 responses (Figures 2 and 4). More recently, it has been shown that there are a high proportion of $\mathrm{CD}_{25} 5^{-}$Foxp $3^{+}$Treg cell in the lungs of B. pertussis-infected mice and these cells work with IL-10-secreting Treg cells to subvert bacterial clearance by modulating Th1 responses. ${ }^{32}$ In addition to facilitating persistence of the bacteria, these regulatory responses may be of benefit to the host by limiting immune-mediated pathology. ${ }^{26}$

\section{B. PERTUSSIS VIRULENCE FACTORS-PROTECTIVE ANTIGENS AND IMMUNOMODULATORY MOLECULES}

B. pertussis causes a persistent respiratory tract infection, lasting many weeks or months in human infants and is often associated with secondary infections and pneumonia. Immunocompetent adult mice do not clear the infection until 5-7 weeks post aerosol challenge with B. pertussis. Furthermore, B. pertussisspecific adaptive immune responses are slow to develop during the course of infection in naive mice ${ }^{20}$ (Figure 1). This is a reflection of the fact that $B$. pertussis has evolved strategies to survive and multiply within several different intracellular and extracellular environments and a variety of strategies to subvert immune responses, including the induction of immunosuppressive cytokines by innate cells ${ }^{107-110}$ and the generation of Treg cells ${ }^{32,105}$ (Figure 5). The number and nature of virulence factors required to effect those strategies, and the regulatory 

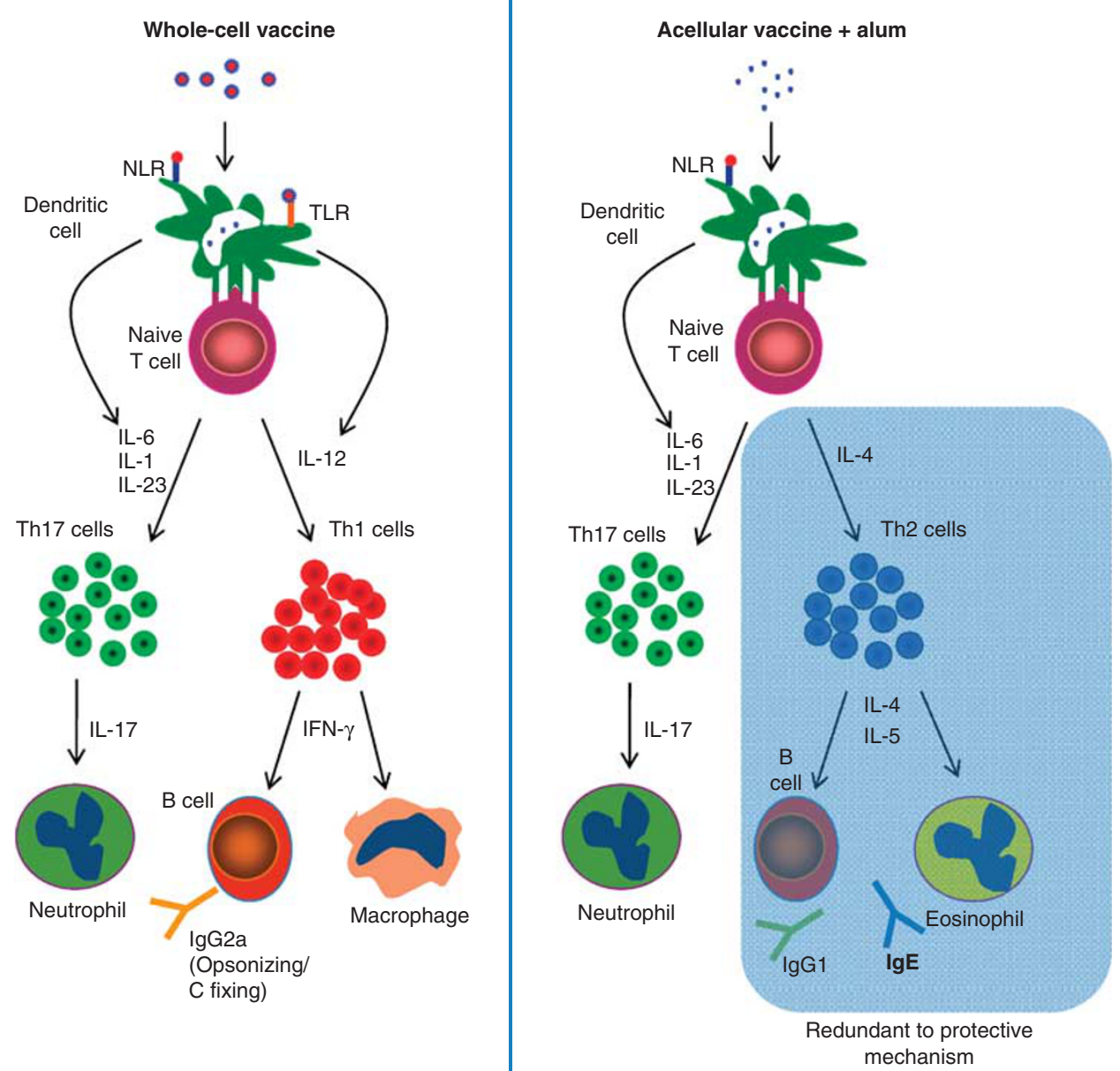

Figure 4 Distinct mechanisms of immunity induced with whole-cell and acellular vaccines (WP and aP, respectively). wP includes pathogenassociated molecular patterns (PAMPs), such as lipopolysaccharide, which activates interleukin (IL)-1, IL-6, IL-12, and IL-23 production by dendritic cells and macrophages. These pro-inflammatory cytokines promote the induction of T helper type 1 (Th1) and Th17 cells from naive T cells. Cytokines secreted by T cells, interferon (IFN)- $\gamma$ from Th1 cells and IL-17 from Th17 cells, provide help for opsonizing antibody production and activate macrophages and neutrophils to take up and kill intracellular bacteria. By contrast, aP is devoid of PAMPs (that stimulate IL-1, IL-12, and IL-23), but include the adjuvant alum, which stimulates IL-1 production, and consequently Th17 cells. Th17 cell help to recruit and activate neutrophils, which take up and kill Bordetella pertussis. Th2 cells are also induced through the influence of IL-4 by an unidentified cell. Th2 cells provide help for B cells to secrete immunoglobulin $\mathrm{E}(\mathrm{IgE})$ and murine $\operatorname{lgG} 1$, IgG3 antibodies, which neutralize toxins and prevent adherence of bacteria in the respiratory tract. However, the Th2 responses are not required for protective immunity in mice. NLR, NOD-like receptor; TLR, Toll-like receptor.

systems that control virulence gene expression are the result of co-evolution between the bacteria and its host. ${ }^{111}$

\section{FHA}

FHA is the major B. pertussis adhesin expressed at the bacterial cell surface and is also secreted into the extracellular milieu. It contains several domains that promote bacterial adherence to ciliated respiratory epithelial cells, including RGD (ArgGly-Asp), carbohydrate-recognition, and heparin-binding domains. ${ }^{112,113}$ FHA-mediated adherence to the respiratory epithelium is enhanced in the presence of $\mathrm{ACT}^{114}$ and cholesterol-containing lipid rafts, ${ }^{115}$ and is associated with increased intracellular adhesion molecule 1 expression. ${ }^{116} \mathrm{FHA}$ also promotes phagocytosis of $B$. pertussis by macrophages and poly- morphonuclear leukocytes, an effect that was inhibited in vitro by anti-FHA antibodies from $B$. pertussis-infected children. ${ }^{117}$ FHA initiates phagocytosis by binding and activating the leukocyte integrin complement receptor 3 on macrophages and other cells, ${ }^{118}$ following which toxin-mediated suppression of intracellular killing promotes bacterial survival..$^{23}$ Antibodies to FHA have a protective role against B. pertussis infection in mice, although studies in mice and humans suggest that it is not a key protective antigen. ${ }^{66,73}$

In addition to its role in bacterial adherence and phagocytosis, secreted FHA also has important immunomodulatory functions, ${ }^{113}$ including the induction of IL- 6 and IL-10 and suppressing IL-12 production by macrophages and DCs. ${ }^{31,106}$ This leads to the generation of IL-10-producing Treg cells that 


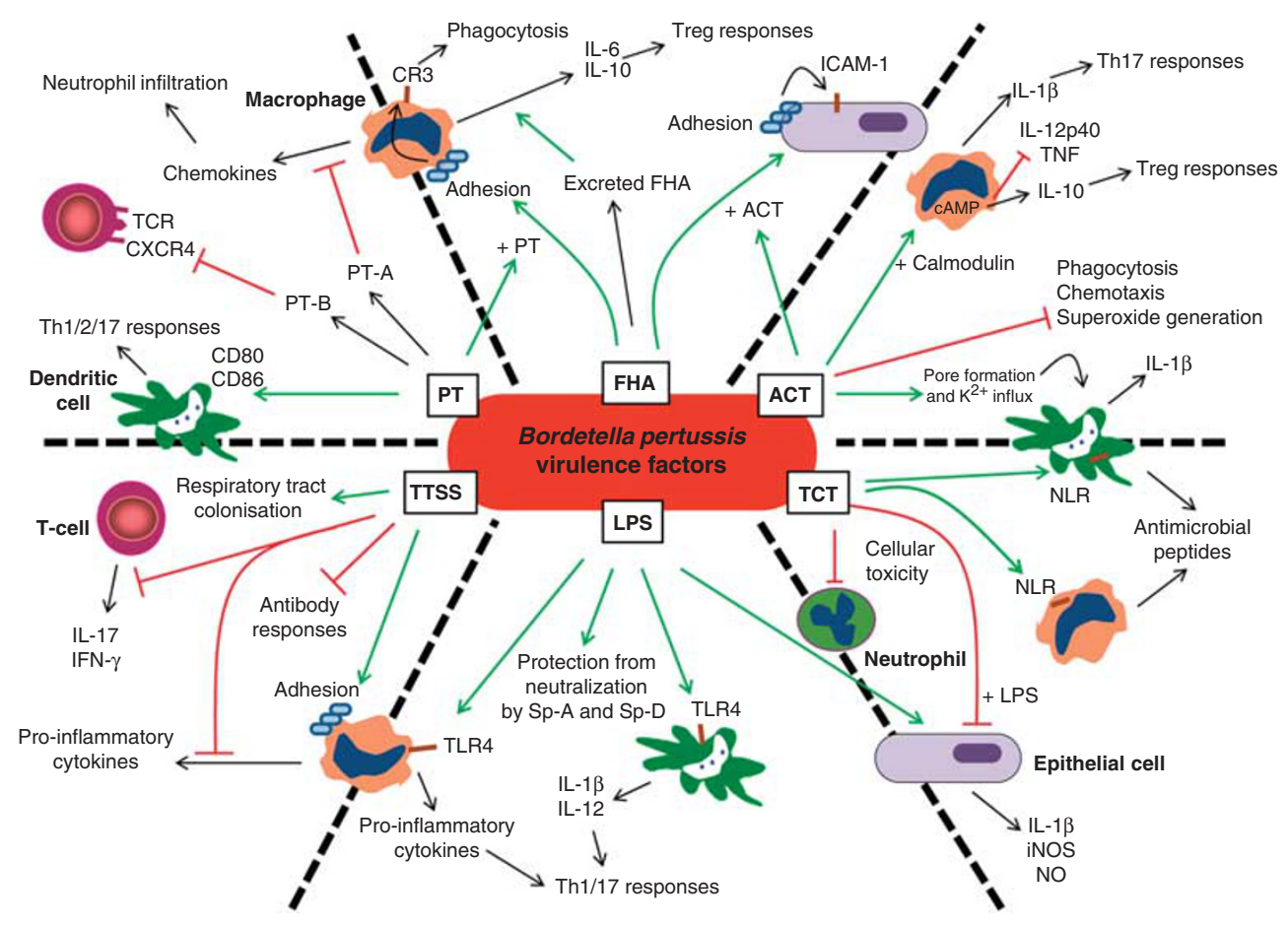

Figure 5 Immunomodulatory effects of Bordetella pertussis virulence factors. A combination of the properties and activities of filamentous hemagglutinin (FHA), pertussis toxin (PT), tracheal cytotoxin (TCT), adenylate cyclase toxin (ACT), type III secretion system (TTSS), and lipopolysaccharide (LPS) provide B. pertussis with multiple mechanisms to evade detection and elimination by the host immune response. Selected effects of individual virulence factors are separated by black dashed lines. Green arrows indicate a positive regulatory effect on the target cell or process. Red bars indicate a negative regulatory effect on the target cell or process. Cells crossing the black dashed lines are targeted by the virulence factor on either side of the line; this layout is for presentation purposes only and does not imply that there is any association between these separate effects. ICAM-1, intracellular adhesion molecule 1 ; IL, interleukin; iNOS, inducible nitric oxide synthase; NLR, nucleotide-binding and oligomerization domain (NOD)-like receptor; NO, nitric oxide; SP, surfactant protein; TCR, T-cell receptor; Th, T helper; TNF, tumor necrosis factor; Treg, regulatory T cells.

suppress IFN- $\gamma$ production and thus inhibit the generation and function of Th1 cells. ${ }^{31,106}$ Furthermore, monocyte-derived IL-10 has recently been shown to inhibit FHA-induced IFN- $\gamma$ secretion by mononuclear cells from vaccinated infants, suggesting that FHA has an immunosuppressive function during infection of humans with B. pertussis. ${ }^{119}$ It has also been reported that B. pertussis FHA can interfere with nuclear factor $\kappa \mathrm{B}$ signalling leading to suppressed immune responses, which was attributed to inhibition of proteasome activity. ${ }^{120}$ Finally, a recent study of the genome-wide transcriptional response of human peripheral blood mononuclear cells to $B$. pertussis FHA showed immunomodulatory effects on several members of the type I IFN and the ISGylation pathways. ${ }^{121}$

\section{PT}

$\mathrm{PT}$ is a secreted virulence factor and a key protective antigen of $B$. pertussis; detoxified $\mathrm{PT}$ is a component of all aP vaccines licensed to date. PT consists of an A monomer with catalytic adenosine diphosphate (ADP) ribosyltransferase activity and a $B$ oligomer that binds surface glycoproteins on a variety of host cells. ${ }^{122-124} \mathrm{PT}$ is known to promote several systemic effects, such as lymphocytosis and histamine sensitisation, and also has adjuvant activity, promoting T-cell responses to bystander antigens. ${ }^{125}$ Following infection, PT initially facilitates FHA-mediated adhesion of B. pertussis to macrophages by mimicking eukaryotic $\mathrm{P}$ - and E-selectins and thereby upregulating complement receptor 3 (CR3; CD11b/CD18) expression.

The different subunits of PT contribute to the immunomodulatory effects on host cells, and can either promote or suppress host immune responses. The A subunit inactivates cytoplasmic $G$ proteins, which inhibits several chemokine signalling pathways and leads to impaired macrophage, neutrophil, and lymphocyte chemotaxis. ${ }^{126} \mathrm{PT}$ has been shown to inhibit phagocytosis by antigen-presenting cell, antigen processing and presentation, and trafficking of antigen-presenting cells to lymph nodes. ${ }^{127,128}$ In addition, the B oligomer of PT activates several T-cell receptor-associated signalling molecules in lymphocytes, including Zap70 and protein kinase $\mathrm{C},{ }^{129}$ which can subsequently promote immunosuppression via cross-desensitisation of the T-cell receptor and the chemokine receptor CXCR4. ${ }^{130}$ Studies of mice infected with a mutant $B$. pertussis strain lacking the ptx gene, ${ }^{98,131,132}$ or treated with recombinant PT, ${ }^{133}$ collectively found that PT inhibited chemokine expression, neutrophil recruitment to the lungs, serum antibody levels, and bacterial clearance. Indeed, these immunosuppressive effects of PT can leave mice more susceptible to subsequent infection with influenza virus. ${ }^{134}$ However, other studies have shown that PT can enhance CD80/CD86 co-stimulatory molecules, 
specific serum IgG levels, and Th1, Th2, and Th17 cytokine responses..$^{97,125}$ Furthermore, PT enhances the severity of experimental autoimmune diseases by activating antigen-presenting cells and Th1 and Th17 cell responses ${ }^{135-137}$ and by inhibiting Treg cells. ${ }^{138,139}$ These conflicting reports of the effects of PT might be attributable to multiple experimental factors, such as single vs. repetitive exposure of host cells to the toxin, which could tip the balance towards either a pro-inflammatory or anti-inflammatory response. ${ }^{140}$

\section{PRN}

PRN is a $69-\mathrm{kDa}$ outer membrane autotransporter protein that has a role in adherence of $B$. pertussis to monocytes and epithelial cells. ${ }^{141,142}$ PRN has an RGD motif, which is involved in integrin-mediated adherence. ${ }^{143}$ Studies with $B$. bronchiseptica have suggested that PRN has a critical role in resistance to neutrophil-mediated clearance. ${ }^{144}$ However, it does not appear to have a major role in persistence of $B$. pertussis, as PRN-deleted mutants of $B$. pertussis were capable of colonizing and multiplying in the respiratory tract of mice. ${ }^{145}$ However, immunization experiments have shown that $\mathrm{PRN}$ is a protective antigen in mice. ${ }^{146} \mathrm{PRN}$ is also an important target for antibodies in humans $\mathrm{s}^{66,67}$ and is a component of most aP vaccines in use today. Furthermore, vaccine-driven antigen variation in PRN has been implicated in escape from immunity to B. pertussis. ${ }^{147}$

\section{ACT}

ACT is a post-translationally acylated bifunctional toxin that preferentially targets cells of the innate immune system by binding to the complement receptor 3 complex on the cell surface, ${ }^{148}$ but can also intoxicate complement receptor 3-negative cells. ${ }^{149}$ ACT inhibits the anti-bacterial functions of innate cells by inducing apoptosis and cell cycle arrest and inhibiting phagocytosis, chemotaxis, and superoxide generation. ${ }^{150-153}$ ACT also modulates antigen-presenting cell function and the induction of T-cell responses. ${ }^{107,153,154} \mathrm{ACT}$ is activated by calmodulin binding and catalyses the formation of supraphysiological levels of cAMP, which inhibits the anti-bacterial function of macrophages and suppresses the secretion of the inflammatory cytokines IL-12p70 and TNF- $\alpha$, and promotes secretion of IL-10. ${ }^{107,108}$ Together with IL-10 induced by FHA ${ }^{31}$ and TTSS, $, 85,109,110$ this promotes the development of antigen-specific Tr1-type Treg cells, which subvert the host immune response and delay the clearance of the bacteria. ${ }^{107,108,155}$ However, ACT also promotes inflammatory responses and acts synergistically with TLR2 and TLR4 to increase COX-2 expression. ${ }^{156}$ Furthermore, the hydrophobic C-terminal domain of ACT forms pores in the target cell membrane causing $\mathrm{K}+$ efflux, ${ }^{157}$ which promotes the formation and activation of the NLRP3 inflammasome complex resulting in the activation of caspase- 1 and the release of bio-active IL- $1 \beta$ from LPS-primed DC. ${ }^{29}$ This IL- $1 \beta$ is critical for host protection and clearance of B. pertussis via the induction of IL-17-producing Th17 cells and the recruitment of neutrophils to the site of infection. ${ }^{29}$ Immunization with ACT can induce a level of protective immunity in mouse models, ${ }^{158,159}$ and may be a useful addition to aP, but has not yet been assessed as a vaccine antigen in humans.

\section{LPS}

The LPS molecule of $B$. pertussis lacks the $\mathrm{O}$ antigen of other bacterial LPS structures and is, therefore, more correctly referred to as lipooligosaccharide. ${ }^{160}$ Studies with $B$. pertussis containing a mutated LPS (deletion of $w l b$ locus, leaving LPS molecules consisting of lipid A and core oligosaccharide), have shown that this virulence factor is required for colonisation and survival of Bordetella in vivo. ${ }^{161}$ Similar to LPS from other Gram-negative bacteria, LPS from Bordetella species is pyrogenic, mitogenic, toxic, and can activate pro-inflammatory cytokine production from macrophages. ${ }^{162,163}$ Studies with TLR4-defective mice suggested that LPS signaling mediated through TLR4 was required for the robust innate response in eliciting protective immunity against B. pertussis. ${ }^{27}$ TLR4-defective mice had higher bacterial colonization of the lungs, increased cellular infiltrate, and increased lung pathology. ${ }^{27}$ However, it has also been reported that immune responses triggered early in infection via TLR4 can impair colonization with $B$. pertussis. ${ }^{163}$ Independent of its immunostimulatory capacity, the LPS moiety of $B$. pertussis is also thought to act as a shield, through steric hindrance, protecting the bacterium from neutralization by the pulmonary collectins surfactant protein A and surfactant protein D. ${ }^{50,164}$

LPS is present in varying concentrations in most $\mathrm{wP}$ and in combination with other toxins, in particular PT, it is responsible for wP reactogenicity, including systemic and neurological effects. ${ }^{165-167}$ However, removal of LPS can decrease the efficacy of wP. ${ }^{168}$ It appears that LPS is required for the adjuvant effect of $\mathrm{wP}$, through the induction of IL-12, required for the differentiation of naive $\mathrm{T}$ cell to Th1 cells ${ }^{94}$ and $\mathrm{IL}-1 \beta$ production, which promotes Th17 responses. Further evidence of a role for LPS in the protective efficacy of $\mathrm{wP}$ was provided by the demonstration that $\mathrm{wP}$ failed to generate protective immunity in TLR4-defective mice; ${ }^{26}$ antigen-specific IL-17 and IFN- $\gamma$ production was significantly lower in wP-immunized TLR4-defective mice. ${ }^{26}$ Furthermore, the protective efficacy of $\mathrm{wP}_{\mathrm{P}}$ was reduced in IFN$\gamma$ R-defective mice ${ }^{73}$ or by neutralization of IL-17, ${ }^{26}$ suggesting that LPS contributed to $\mathrm{wP}$-induced immunity by promoting the induction of Th1 and Th17 cells.

\section{TCT}

TCT is a $9.2-\mathrm{kDa}$ disaccharide-tetrapeptide monomer of peptidoglycan that is secreted by growing $B$. pertussis. ${ }^{169}$ TCT is a muramyl peptide, a group of structurally related molecules that bind to the intracellular nucleotide-binding and oligomerization domain (NOD)-like receptors (NLRs), NOD-1 and NOD-2. NOD-1 was found to be the innate immune sensory receptor for TCT in mice, but not in humans. ${ }^{170}$ This differential recognition was shown to be dependent on a structural preference for DAP-containing tetrapeptide muramyl peptides (M-Tetra ${ }_{\text {DAP }}$ ) by murine NOD-1 and DAP-containing tripeptide muramyl peptides $\left(\mathrm{M}-\mathrm{Tri}_{\mathrm{DAP}}\right)$ by human NOD-1. ${ }^{170}$ TCT also activates the immune deficiency pathway, an ancient innate defense pathway required for antimicrobial gene expression in response to Gram-negative bacteria. ${ }^{171}$

TCT induces cytopathology in hamster tracheal ring organ cultures (loss of cilia, disruption of tight junctions, and extrusion 
of ciliated cells from the respiratory surface) similar to the pathology observed during pertussis in humans. ${ }^{169,172}$ TCT also inhibits DNA synthesis in cultured hamster tracheal epithelial cells. ${ }^{169}$ TCT-mediated inhibition of proliferation of these cells may reflect a secondary effect of TCT on the capacity of respiratory epithelium to regenerate the lost ciliated cell population. ${ }^{169}$ IL-1 has been implicated in TCT-mediated toxicity; TCT stimulates IL- $1 \alpha$ production by respiratory epithelial cells and recombinant IL- $1 \alpha$ inhibits DNA synthesis and causes destruction of epithelial cells in hamster tracheal organ culture. ${ }^{173}$ TCT and LPS have been found to act in synergy to induce IL- $1 \alpha$, inducible NOS, NO, and the inhibition of DNA synthesis by epithelial cells. ${ }^{174}$ TCT is also toxic to human neutrophils. ${ }^{175}$

\section{TTSS}

The TTSS is a needle-like structure that enables invading bacteria to inject effector proteins into host cells. ${ }^{176}$ Although the majority of Bordetella TTSS research to date has focused on B. bronchiseptica, the TTSS of $B$. pertussis has been shown to be functional and subvert both innate and adaptive host immune responses. ${ }^{85}$ Mice infected with TTSS-deficient $B$. pertussis (harbouring a $b s c N$ mutation) had lower bacterial colonization and greater pro-inflammatory cytokine release in the lungs, and higher antigen-specific IL-17 and IFN- $\gamma$ production than mice infected with wild-type bacteria. ${ }^{85}$

Early work demonstrated that $B$. pertussis has a bsc locus containing multiple TTSS genes, ${ }^{177,178}$ although a posttranscriptional event prevented the secretion of TTSS proteins. ${ }^{179}$ More recent work has shown that although B. pertussis does express a functional TSSS, not all strains express the full complement of TTSS proteins; expression of the TTSS protein Bsp22, for example, was detected in 15 of 16 clinical isolates of $B$. pertussis and in low-passage strains, but not in the common Tahoma I laboratory strain. ${ }^{85}$ Two further TTSS proteins, BopD and BopN, were also detected in the low-passage strain B. pertussis 12743, but not in the Tahoma I strain, whereas BteA (also called BopC) was not detected in any of the $B$. pertussis strains investigated in this study. ${ }^{85}$ The lack of expression of BteA in certain B. pertussis strains is due to an IS481 insertion in the $5^{\prime}$ untranslated region of the gene, resulting in BteA being expressed at higher levels in B. pertussis non-vaccine-type strains than in vaccine-type strains. ${ }^{180}$ A lack of BteA expression might explain the inability of $B$. pertussis 12743 to mediate cytotoxicty in vitro, ${ }^{85}$ as B. bronchiseptica BteA protein has been shown to induce necrosis and tyrosine dephosphorylation in host cells, ${ }^{181}$ although this is unclear as BteA-expressing strains of $B$. pertussis showed low cytotoxicity in a separate study. ${ }^{180}$ Furthermore, laboratory adaptation and long-term passaging was associated with a loss of TTSS protein expression in both the laboratory and clinical B. pertussis strains, although this could be reversed when the inactivated strains were used to infect mice. ${ }^{182}$ Taken together, these findings suggest that the TTSS expression profile of highly passaged laboratory strains may not reflect that of clinically relevant strains that infect humans, which may have serious implications for vaccine efficacy.

\section{CONCLUSIONS AND PERSPECTIVES ON FUTURE PERTUSSIS VACCINES}

Major questions that need to be addressed in the field of pertussis include, should the aP be updated to include a more relevant adjuvant or different antigenic components, and should adolescents and adults be vaccinated in an attempt to prevent the carriage and spread of $B$. pertussis and reduce the global incidence of this disease? Given the increasing incidence of pertussis in vaccinated populations, ${ }^{1,2}$ strategies to raise the efficacy and longevity of the protection induced by aP to that of the original wP should be investigated taking cognisance of recent discoveries on the mechanisms of vaccine-induced immunity, especially the role of T-cell subtypes.

The lower efficacy of aP compared with wP may reflect faster waning of immunity induced by aP. It may also be caused by selection pressure and antigenic variation, which allow the circulating B. pertussis strains to escape immunity induced by the antigens in aP, as they are derived from the historic laboratory strains. ${ }^{6,183,184}$ Alternatively, it may reflect the choice of adjuvant for existing aP. Currently, aP are administered with alum as the adjuvant and although having a long history of safety in humans, alum favors the induction of Th2 cells and antibodies. Recent studies in our laboratory have shown that $\mathrm{wP}$ or natural infection, which induce relatively high levels of protection, promote Th1 and Th17 responses, whereas aP induces Th17 and Th2 cells in mice (Ross and Mills, unpublished). Therefore, introduction of alternative adjuvants that favor the induction of Th1 cells, ${ }^{94,185,186}$ will provide better protection against B. pertussis than a vaccine formulated with alum. ${ }^{103}$ Furthermore, as aP are known to be more efficacious when they include a higher number or antigens, 2,62 the inclusion of additional antigens from B. pertussis that are known to contribute to protective immunity, such as ACT and BrkA, ${ }^{158,159,187}$ could improve the levels of protection induced by aP.

\section{ACKNOWLEDGMENTS}

This work was supported by Science Foundation Ireland, SRC and PI grants to Kingston Mills.

\section{DISCLOSURE}

K.H.G.M. is a co-founder and shareholder in Opsona Therapeutics and TriMod Therapeutics, University start-up companies involved in the development of immunotherapeutics. None of the other authors have any potential conflicts of interest.

\section{(c) 2012 Society for Mucosal Immunology}

\section{REFERENCES}

1. Black, R.E. et al. Global, regional, and national causes of child mortality in 2008: a systematic analysis. Lancet 375, 1969-1987 (2010).

2. Cherry, J.D. The present and future control of pertussis. Clin. Infect. Dis. 51, 663-667 (2010)

3. Centers for Disease, C. \& Prevention.. Notes from the field: Pertussis California, January-June 2010. MMWR Morb. Mortal. Wkly. Rep. 59, 817 (2010).

4. Barret, A.S. et al. Pertussis outbreak in northwest Ireland, January - June 2010. Euro Surveill. 15, pii=19654 (2010).

5. Roper, K. Outbreak of pertussis, 1 January to 31 March 2009. Commun. Dis. Intell. 33, 36-37 (2009).

6. Octavia, S. et al. Newly emerging clones of Bordetella pertussis carrying prn2 and ptxP3 alleles implicated in Australian Pertussis epidemic in 2008-2010. J. Infect. Dis. 205, 1220-1224 (2012). 
7. Ryan, M. et al. Bordetella pertussis respiratory infection in children is associated with preferential activation of type $1 \mathrm{~T}$ helper cells. J. Infect. Dis. 175, 1246-1250 (1997).

8. Mascart, F. et al. Bordetella pertussis infection in 2-month-old infants promotes type 1T cell responses. J. Immunol. 170, 1504-1509 (2003).

9. Mahon, B.P., Sheahan, B.J., Griffin, F., Murphy, G. \& Mills, K.H. Atypical disease after Bordetella pertussis respiratory infection of mice with targeted disruptions of interferon-gamma receptor or immunoglobulin mu chain genes. J. Exp. Med. 186, 1843-1851 (1997).

10. Barbic, J., Leef, M.F., Burns, D.L. \& Shahin, R.D. Role of gamma interferon in natural clearance of Bordetella pertussis infection. Infect. Immun. 65, 4904-4908 (1997).

11. Mills, K.H., Barnard, A., Watkins, J. \& Redhead, K. Cell-mediated immunity to Bordetella pertussis: role of Th1 cells in bacterial clearance in a murine respiratory infection model. Infect. Immun. 61, 399-410 (1993).

12. Dunne, P.J., Moran, B., Cummins, R.C. \& Mills, K.H. CD11c+CD8 $\{a l p h a \mid\}+$ dendritic cells promote protective immunity to respiratory infection with Bordetella pertussis. J. Immunol. 183, 400-410 (2009).

13. Byrne, P., McGuirk, P., Todryk, S. \& Mills, K.H. Depletion of NK cells results in disseminating lethal infection with Bordetella pertussis associated with a reduction of antigen-specific Th1 and enhancement of Th2, but not Tr1 cells. Eur. J. Immunol. 34, 2579-2588 (2004).

14. Ryan, M. et al. Distinct T-cell subtypes induced with whole cell and acellular pertussis vaccines in children. Immunology 93, 1-10 (1998).

15. Ausiello, C.M., Urbani, F., la Sala, A., Lande, R. \& Cassone, A. Vaccineand antigen-dependent type 1 and type 2 cytokine induction after primary vaccination of infants with whole-cell or acellular pertussis vaccines. Infect. Immun. 65, 2168-2174 (1997).

16. Carbonetti, N.H., Artamonova, G.V., Van Rooijen, N. \& Ayala, V.I. Pertussis toxin targets airway macrophages to promote Bordetella pertussis infection of the respiratory tract. Infect. Immun. 75, 1713-1720 (2007).

17. Lamberti, Y.A., Hayes, J.A., Perez Vidakovics, M.L., Harvill, E.T. \& Rodriguez, M.E. Intracellular trafficking of Bordetella pertussis in human macrophages. Infect. Immun. 78, 907-913 (2010).

18. Paddock, C.D. et al. Pathology and pathogenesis of fatal Bordetella pertussis infection in infants. Clin. Infect. Dis. 47, 328-338 (2008).

19. Hellwig. S.M., Hazenbos, W.L., van de Winkel, J.G. \& Mooi, F.R. Evidence for an intracellular niche for Bordetella pertussis in bronchoalveolar lavage cells of mice. FEMS Immunol. Med. Microbiol. 26, 203-207 (1999).

20. McGuirk, P., Mahon, B.P., Griffin, F. \& Mills, K.H. Compartmentalization of $T$ cell responses following respiratory infection with Bordetella pertussis: hyporesponsiveness of lung T cells is associated with modulated expression of the co-stimulatory molecule CD28. Eur. J. Immunol. 28, 153-163 (1998).

21. Bromberg, K., Tannis, G. \& Steiner, P. Detection of Bordetella pertussis associated with the alveolar macrophages of children with human immunodeficiency virus infection. Infect. Immun. 59, 4715-4719 (1991).

22. Saukkonen, K., Cabellos, C., Burroughs, M., Prasad, S. \& Tuomanen, E. Integrin-mediated localization of Bordetella pertussis within macrophages: role in pulmonary colonization. J. Exp. Med. 173, 1143-1149 (1991).

23. Friedman, R.L., Nordensson, K., Wilson, L., Akporiaye, E.T. \& Yocum, D.E. Uptake and intracellular survival of Bordetella pertussis in human macrophages. Infect. Immun. 60, 4578-4585 (1992).

24. Lamberti, Y.A., Hayes, J.A., Perez Vidakovics, M.L., Harvill, E.T. \& Rodriguez, M.E. Intracellular trafficking of Bordetella pertussis in human macrophages. Infect. Immun. 78, 907-913 (2010).

25. Mahon, B.P. \& Mills, K.H. Interferon-gamma mediated immune effector mechanisms against Bordetella pertussis. Immunol. Lett. 68, 213-217 (1999).

26. Higgins, S.C., Jarnicki, A.G., Lavelle, E.C. \& Mills, K.H. TLR4 mediates vaccine-induced protective cellular immunity to Bordetella pertussis: role of IL-17-producing T cells. J. Immunol. 177, 7980-7989 (2006).

27. Higgins, S.C. et al. Toll-like receptor 4-mediated innate IL-10 activates antigen-specific regulatory $T$ cells and confers resistance to Bordetella pertussis by inhibiting inflammatory pathology. J. Immunol. 171, 3119-3127 (2003)
28. Banus, H.A. et al. Host genetics of Bordetella pertussis infection in mice: significance of Toll-like receptor 4 in genetic susceptibility and pathobiology. Infect. Immun. 74, 2596-2605 (2006).

29. Dunne, A. et al. Inflammasome activation by adenylate cyclase toxin directs Th17 responses and protection against Bordetella pertussis. J. Immunol. 185, 1711-1719 (2010).

30. Fedele, G. et al. Bordetella pertussis commits human dendritic cells to promote a Th1/Th17 response through the activity of adenylate cyclase toxin and MAPK-pathways. PLoS One 5, e8734 (2010).

31. McGuirk, P., McCann, C. \& Mills, K.H. Pathogen-specific T regulatory 1 cells induced in the respiratory tract by a bacterial molecule that stimulates interleukin 10 production by dendritic cells: a novel strategy for evasion of protective Thelper type 1 responses by Bordetella pertussis. J. Exp. Med. 195, 221-231 (2002).

32. Coleman, M.M. et al. The immunoregulatory role of CD4(+) FoxP3(+) CD25(-) regulatory T cells in lungs of mice infected with Bordetella pertussis. FEMS Immunol. Med. Microbiol. (2011).

33. Lamberti, Y., Perez Vidakovics, M.L., van der Pol, L.W. \& Rodriguez, M.E. Cholesterol-rich domains are involved in Bordetella pertussis phagocytosis and intracellular survival in neutrophils. Microb. Pathog. 44, 501-511 (2008)

34. McGuirk, P. \& Mills, K.H. A regulatory role for interleukin 4 in differential inflammatory responses in the lung following infection of mice primed with Th1 - or Th2-inducing pertussis vaccines. Infect. Immun. 68, 1383-1390 (2000).

35. Zhang, X., Goel, T., Goodfield, L.L., Muse, S.J. \& Harvill, E.T. Decreased leukocyte accumulation and delayed Bordetella pertussis clearance in IL-6-/- mice. J. Immunol. 186, 4895-4904 (2011).

36. Andreasen, C. \& Carbonetti, N.H. Role of neutrophils in response to Bordetella pertussis infection in mice. Infect. Immun. 77, 1182-1188 (2009).

37. Confer, D.L. \& Eaton, J.W. Pathogen-host jujitsu: phagocyte impotence caused by internalized bacterial adenylate cyclase. Trans. Assoc. Am Physicians 95, 1-7 (1982).

38. Harvill, E.T., Cotter, P.A. \& Miller, J.F. Pregenomic comparative analysis between Bordetella bronchiseptica RB50 and Bordetella pertussis tohama I in murine models of respiratory tract infection. Infect. Immun. 67, 6109-6118 (1999).

39. Travis, S.M., Singh, P.K. \& Welsh, M.J. Antimicrobial peptides and proteins in the innate defense of the airway surface. Curr. Opin. Immunol. 13, 89-95 (2001).

40. Fernandez, R.C. \& Weiss, A.A. Susceptibilities of Bordetella pertussis strains to antimicrobial peptides. Antimicrob. Agents Chemother. 40, 1041-1043 (1996).

41. Elahi, S. et al. The host defense peptide beta-defensin 1 confers protection against Bordetella pertussis in newborn piglets. Infect. Immun. 74, 2338-2352 (2006).

42. Erles, K. \& Brownlie, J. Expression of beta-defensins in the canine respiratory tract and antimicrobial activity against Bordetella bronchiseptica. Vet. Immunol. Immunopathol. 135, 12-19 (2010).

43. Elahi, S. et al. Infection with Bordetella parapertussis but not Bordetella pertussis causes pertussis-like disease in older pigs. J. Infect. Dis. 198, 384-392 (2008)

44. Legarda, D., Klein-Patel, M.E., Yim, S., Yuk, M.H. \& Diamond, G. Suppression of NF-kappaB-mediated beta-defensin gene expression in the mammalian airway by the Bordetella type III secretion system. Cell Microbiol. 7, 489-497 (2005).

45. Kao, C.Y. et al. IL-17 markedly up-regulates beta-defensin-2 expression in human airway epithelium via JAK and NF-kappaB signaling pathways. J. Immunol. 173, 3482-3491 (2004).

46. Fernandez, R.C. \& Weiss, A.A. Cloning and sequencing of a Bordetella pertussis serum resistance locus. Infect. Immun. 62, 4727-4738 (1994).

47. Barnes, M.G. \& Weiss, A.A. BrkA protein of Bordetella pertussis inhibits the classical pathway of complement after $\mathrm{C} 1$ deposition. Infect. Immun. 69, 3067-3072 (2001).

48. Weiss, A.A., Mobberley, P.S., Fernandez, R.C. \& Mink, C.M. Characterization of human bactericidal antibodies to Bordetella pertussis. Infect. Immun. 67, 1424-1431 (1999).

49. Barnes, M.G. \& Weiss, A.A. Growth phase influences complement resistance of Bordetella pertussis. Infect. Immun. 70, 403-406 (2002). 
50. Pishko, E.J., Betting, D.J., Hutter, C.S. \& Harvill, E.T. Bordetella pertussis acquires resistance to complement-mediated killing in vivo. Infect. Immun. 71, 4936-4942 (2003).

51. Goebel, E.M., Wolfe, D.N., Elder, K., Stibitz, S. \& Harvill, E.T. O antigen protects Bordetella parapertussis from complement. Infect. Immun. 76, 1774-1780 (2008).

52. Berggard, K., Johnsson, E., Mooi, F.R. \& Lindahl, G. Bordetella pertussis binds the human complement regulator C4BP: role of filamentous hemagglutinin. Infect. Immun. 65, 3638-3643 (1997).

53. Marr, N., Luu, R.A. \& Fernandez, R.C. Bordetella pertussis binds human C1 esterase inhibitor during the virulent phase, to evade complementmediated killing. J. Infect. Dis. 195, 585-588 (2007).

54. Barnes, M.G. \& Weiss, A.A. Activation of the complement cascade by Bordetella pertussis. FEMS Microbiol. Lett. 220, 271-275 (2003).

55. Amdahl, H. et al. Interactions between Bordetella pertussis and the complement inhibitor factor H. Mol. Immunol. 48, 697-705 (2011).

56. Hellwig, S.M., van Spriel, A.B., Schellekens, J.F., Mooi, F.R. \& van de Winkel, J.G. Immunoglobulin A-mediated protection against Bordetella pertussis infection. Infect. Immun. 69, 4846-4850 (2001).

57. Quinello, C., Quintilio, W., Carneiro-Sampaio, M. \& Palmeira, P. Passive acquisition of protective antibodies reactive with Bordetella pertussis in newborns via placental transfer and breast-feeding. Scand. J. Immunol. 72, 66-73 (2010)

58. Mills, K.H. Immunity to Bordetella pertussis. Microbes Infect. 3, 655-677 (2001).

59. Mielcarek, N. et al. Live attenuated B. pertussis as a single-dose nasal vaccine against whooping cough. PLoS Pathog. 2, e65 (2006).

60. Granstrom, M., Olinder-Nielsen, A.M., Holmblad, P., Mark, A. \& Hanngren, K. Specific immunoglobulin for treatment of whooping cough. Lancet 338, 1230-1233 (1991).

61. Simondon, F. et al. A randomized double-blind trial comparing a twocomponent acellular to a whole-cell pertussis vaccine in Senegal. Vaccine 15, 1606-1612 (1997)

62. Olin, P., Rasmussen, F., Gustafsson, L., Hallander, H.O. \& Heijbel, H. Randomised controlled trial of two-component, three-component, and five-component acellular pertussis vaccines compared with whole-cell pertussis vaccine. Ad Hoc Group for the Study of Pertussis Vaccines. Lancet 350, 1569-1577 (1997)

63. Greco, D. et al. A controlled trial of two acellular vaccines and one whole-cell vaccine against pertussis. Progetto Pertosse Working Group. N. Engl. J. Med. 334, 341-348 (1996).

64. Gustafsson, L., Hallander, H.O., Olin, P., Reizenstein, E. \& Storsaeter, J. A controlled trial of a two-component acellular, a five-component acellular, and a whole-cell pertussis vaccine. N. Engl. J. Med. 334 349-355 (1996).

65. Trollfors, B. et al. A placebo-controlled trial of a pertussis-toxoid vaccine. N. Engl. J. Med. 333, 1045-1050 (1995).

66. Storsaeter, J., Hallander, H.O., Gustafsson, L. \& Olin, P. Levels of antipertussis antibodies related to protection after household exposure to Bordetella pertussis. Vaccine 16, 1907-1916 (1998).

67. Cherry, J.D., Gornbein, J., Heininger, U. \& Stehr, K. A search for serologic correlates of immunity to Bordetella pertussis cough illnesses. Vaccine 16, 1901-1906 (1998).

68. Taranger, J. et al. Correlation between pertussis toxin IgG antibodies in postvaccination sera and subsequent protection against pertussis. J. Infect. Dis. 181, 1010-1013 (2000).

69. Giuliano, M. et al. Antibody responses and persistence in the two years after immunization with two acellular vaccines and one whole-cell vaccine against pertussis. J. Pediatr. 132, 983-988 (1998).

70. Salmaso, S. et al. Persistence of protection through 33 months of age provided by immunization in infancy with two three-component acellular pertussis vaccines. Stage II Working Group. Vaccine 16, 1270-1275 (1998).

71. Hendrikx, L.H. et al. Enhanced memory B-cell immune responses after a second acellular pertussis booster vaccination in children 9 years of age. Vaccine 30, 51-58 (2011).

72. Mahon, B.P., Brady, M.T. \& Mills, K.H. Protection against Bordetella pertussis in mice in the absence of detectable circulating antibody: implications for long-term immunity in children. J. Infect. Dis. 181, 2087-2091 (2000)

73. Mills, K.H., Ryan, M., Ryan, E. \& Mahon, B.P. A murine model in which protection correlates with pertussis vaccine efficacy in children reveals complementary roles for humoral and cell-mediated immunity in protection against Bordetella pertussis. Infect. Immun. 66, 594-602 (1998).

74. Leef, M., Elkins, K.L., Barbic, J. \& Shahin, R.D. Protective immunity to Bordetella pertussis requires both B cells and CD4(+) T cells for key functions other than specific antibody production. J. Exp. Med. 191, 1841-1852 (2000).

75. Shahin, R.D., Witvliet, M.H. \& Manclark, C.R. Mechanism of pertussis toxin B oligomer-mediated protection against Bordetella pertussis respiratory infection. Infect. Immun. 58, 4063-4068 (1990).

76. Golovkina, T.V., Shlomchik, M., Hannum, L. \& Chervonsky, A. Organogenic role of B lymphocytes in mucosal immunity. Science $\mathbf{2 8 6}$ 1965-1968 (1999).

77. Mosmann, T.R., Cherwinski, H., Bond, M.W., Giedlin, M.A. \& Coffman, R.L. Two types of murine helper T cell clone. I. Definition according to profiles of lymphokine activities and secreted proteins. J. Immunol. 136, 2348-2357 (1986).

78. Sakaguchi, S., Fukuma, K., Kuribayashi, K. \& Masuda, T. Organ-specific autoimmune diseases induced in mice by elimination of $\mathrm{T}$ cell subset. I. Evidence for the active participation of T cells in natural self-tolerance; deficit of a $T$ cell subset as a possible cause of autoimmune disease. J Exp. Med. 161, 72-87 (1985)

79. Langrish, C.L. et al. IL-23 drives a pathogenic T cell population that induces autoimmune inflammation. J. Exp. Med. 201, 233-240 (2005).

80. De Magistris, M.T., Romano, M., Bartoloni, A., Rappuoli, R. \& Tagliabue, A. Human T cell clones define S1 subunit as the most immunogenic moiety of pertussis toxin and determine its epitope map. J. Exp. Med. 169, 1519-1532 (1989)

81. Hafler, J.P. \& Pohl-Koppe, A. The cellular immune response to Bordetella pertussis in two children with whooping cough. Eur. J. Med. Res. 3, 523-526 (1998).

82. Peppoloni, S. et al. Lymphokine secretion and cytotoxic activity of human CD4+ T-cell clones against Bordetella pertussis. Infect. Immun. 59, 3768-3773 (1991).

83. Tran Minh, N.N. et al. Cell-mediated immune responses to antigens of Bordetella pertussis and protection against pertussis in school children. Pediatr. Infect. Dis. J. 18, 366-370 (1999).

84. Ausiello, C.M., Lande, R., la Sala, A., Urbani, F. \& Cassone, A. Cellmediated immune response of healthy adults to Bordetella pertussis vaccine antigens. J. Infect. Dis. 178, 466-470 (1998).

85. Fennelly, N.K. et al. Bordetella pertussis expresses a functional type III secretion system that subverts protective innate and adaptive immune responses. Infect. Immun. 76, 1257-1266 (2008)

86. Cua, D.J. \& Tato, C.M. Innate IL-17-producing cells: the sentinels of the immune system. Nat. Rev. Immunol. 10, 479-489 (2010).

87. Agarwal, S.K. et al. Association of interleukin 23 receptor polymorphisms with anti-topoisomerase-I positivity and pulmonary hypertension in systemic sclerosis. J. Rheumatol. 36, 2715-2723 (2009).

88. Zepp, F. et al. Pertussis-specific cell-mediated immunity in infants after vaccination with a tricomponent acellular pertussis vaccine. Infect. Immun. 64, 4078-4084 (1996).

89. White, O.J. et al. Th2-polarisation of cellular immune memory to neonata

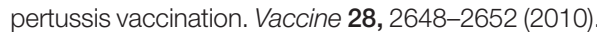

90. Ryan, E.J., Nilsson, L., Kjellman, N., Gothefors, L. \& Mills, K.H. Booster immunization of children with an acellular pertussis vaccine enhances Th2 cytokine production and serum lgE responses against pertussis toxin but not against common allergens. Clin. Exp. Immunol. 121, 193-200 (2000)

91. Ausiello, C.M. et al. Cell-mediated immune responses in four-year-old children after primary immunization with acellular pertussis vaccines. Infect. Immun. 67, 4064-4071 (1999).

92. Skowronski, D.M. et al. Injection-site reactions to booster doses of acellular pertussis vaccine: rate, severity, and anticipated impact. Pediatrics 112, e453 (2003)

93. Zachariadis, O., Cassidy, J.P., Brady, J. \& Mahon, B.P. gammadelta T cells regulate the early inflammatory response to Bordetella pertussis infection in the murine respiratory tract. Infect. Immun. 74, 1837-1845 (2006).

94. Mahon, B.P., Ryan, M.S., Griffin, F. \& Mills, K.H. Interleukin-12 is produced by macrophages in response to live or killed Bordetella pertussis and enhances the efficacy of an acellular pertussis vaccine by promoting induction of Th1 cells. Infect. Immun. 64, 5295-5301 (1996) 
95. Torre, D., Ferrario, G., Bonetta, G., Perversi, L. \& Speranza, F. In vitro and in vivo induction of nitric oxide by murine macrophages stimulated with Bordetella pertussis. FEMS Immunol. Med. Microbiol. 13, 95-99 (1996).

96. Canthaboo, C., Xing, D., Wei, X.Q. \& Corbel, M.J. Investigation of role of nitric oxide in protection from Bordetella pertussis respiratory challenge. Infect. Immun. 70, 679-684 (2002).

97. Andreasen, C., Powell, D.A. \& Carbonetti, N.H. Pertussis toxin stimulates IL-17 production in response to Bordetella pertussis infection in mice. PLoS One 4, e7079 (2009).

98. Kirimanjeswara, G.S., Agosto, L.M., Kennett, M.J., Bjornstad, O.N. \& Harvill, E.T. Pertussis toxin inhibits neutrophil recruitment to delay antibody-mediated clearance of Bordetella pertussis. J. Clin. Invest. 115, 3594-3601 (2005).

99. Redhead, K., Watkins, J., Barnard, A. \& Mills, K.H. Effective immunization against Bordetella pertussis respiratory infection in mice is dependent on induction of cell-mediated immunity. Infect. Immun. 61, 3190-3198 (1993).

100. Barnard, A., Mahon, B.P., Watkins, J., Redhead, K. \& Mills, K.H. Th1/Th2 cell dichotomy in acquired immunity to Bordetella pertussis: variables in the in vivo priming and in vitro cytokine detection techniques affect the classification of T-cell subsets as Th1, Th2 or Th0. Immunology. 87, 372-380 (1996).

101. Ryan, M., Gothefors, L., Storsaeter, J. \& Mills, K.H. Bordetella pertussisspecific Th1/Th2 cells generated following respiratory infection or immunization with an acellular vaccine: comparison of the T cell cytokine profiles in infants and mice. Dev. Biol. Stand. 89, 297-305 (1997).

102. Mills, K.H. \& Redhead, K. Cellular immunity in pertussis. J. Med. Microbiol. 39, 163-164 (1993).

103. Brereton, C.F. et al. Escherichia coli heat-labile enterotoxin promotes protective Th17 responses against infection by driving innate IL- 1 and IL-23 production. J. Immunol. 186, 5896-5906 (2011).

104. Mills, K.H. Regulatory T cells: friend or foe in immunity to infection? Nat. Rev. Immunol. 4, 841-855 (2004).

105. McGuirk, P. \& Mills, K.H. Pathogen-specific regulatory T cells provoke a shift in the Th1/Th2 paradigm in immunity to infectious diseases. Trends Immunol. 23, 450-455 (2002).

106. McGuirk, P. \& Mills, K.H. Direct anti-inflammatory effect of a bacterial virulence factor: IL-10-dependent suppression of IL-12 production by filamentous hemagglutinin from Bordetella pertussis. Eur. J. Immunol. 30, 415-422 (2000).

107. Ross, P.J., Lavelle, E.C., Mills, K.H. \& Boyd, A.P. Adenylate cyclase toxin from Bordetella pertussis synergizes with lipopolysaccharide to promote innate interleukin-10 production and enhances the induction of Th2 and regulatory T cells. Infect. Immun. 72, 1568-1579 (2004).

108. Boyd, A.P. et al. Bordetella pertussis adenylate cyclase toxin modulates innate and adaptive immune responses: distinct roles for acylation and enzymatic activity in immunomodulation and cell death. J. Immunol. 175, 730-738 (2005).

109. Nagamatsu, K. et al. Bordetella evades the host immune system by inducing IL-10 through a type III effector, BopN. J. Exp. Med. 206, 3073-3088 (2009).

110. Skinner, J.A., Reissinger, A., Shen, H. \& Yuk, M.H. Bordetella type III secretion and adenylate cyclase toxin synergize to drive dendritic cells into a semimature state. J. Immunol. 173, 1934-1940 (2004).

111. Cotter, P.A. \& DiRita, V.J. Bacterial virulence gene regulation: an evolutionary perspective. Annu. Rev. Microbiol. 54, 519-565 (2000).

112. Locht, C., Bertin, P., Menozzi, F.D. \& Renauld, G. The filamentous haemagglutinin, a multifaceted adhesion produced by virulent Bordetella spp. Mol. Microbiol. 9, 653-660 (1993).

113. de Gouw, D., Diavatopoulos, D.A., Bootsma, H.J., Hermans, P.W. \& Mooi, F.R. Pertussis: a matter of immune modulation. FEMS Microbiol. Rev. 35, 441-474 (2011).

114. Perez Vidakovics, M.L., Lamberti, Y., van der Pol, W.L., Yantorno, O. \& Rodriguez, M.E. Adenylate cyclase influences filamentous haemagglutinin-mediated attachment of Bordetella pertussis to epithelial alveolar cells. FEMS Immunol. Med. Microbiol. 48, 140-147 (2006).

115. Lamberti, Y., Alvarez Hayes, J., Perez Vidakovics, M.L. \& Rodriguez, M.E. Cholesterol-dependent attachment of human respiratory cells by Bordetella pertussis. FEMS Immunol. Med. Microbiol. 56, 143-150 (2009).

116. Ishibashi, Y. \& Nishikawa, A. Bordetella pertussis infection of human respiratory epithelial cells up-regulates intercellular adhesion molecule-1 expression: role of filamentous hemagglutinin and pertussis toxin. Microb. Pathog. 33, 115-125 (2002).

117. Mobberley-Schuman, P.S., Connelly, B. \& Weiss, A.A. Phagocytosis of Bordetella pertussis incubated with convalescent serum. J. Infect. Dis. 187, 1646-1653 (2003).

118. Relman, D. et al. Recognition of a bacterial adhesion by an integrin: macrophage CR3 (alpha M beta 2, CD11b/CD18) binds filamentous hemagglutinin of Bordetella pertussis. Cell 61, 1375-1382 (1990).

119. Dirix, V. et al. Monocyte-derived interleukin-10 depresses the Bordetella pertussis- specific gamma interferon response in vaccinated infants. Clin. Vaccine Immunol. 16, 1816-1821 (2009).

120. Abramson, T., Kedem, H. \& Relman, D.A. Modulation of the NF-kappaB pathway by Bordetella pertussis filamentous hemagglutinin. PLoS One 3, e3825 (2008).

121. Dieterich, C. \& Relman, D.A. Modulation of the host interferon response and ISGylation pathway by B. pertussis filamentous hemagglutinin. PLoS One 6, e27535 (2011).

122. Lobet, Y. et al. Site-specific alterations in the B oligomer that affect receptor-binding activities and mitogenicity of pertussis toxin. J. Exp. Med. 177, 79-87 (1993).

123. van't Wout, J. et al. Role of carbohydrate recognition domains of pertussis toxin in adherence of Bordetella pertussis to human macrophages. Infect. Immun. 60, 3303-3308 (1992).

124. Saukkonen, K., Burnette, W.N., Mar, V.L., Masure, H.R. \& Tuomanen, E.I. Pertussis toxin has eukaryotic-like carbohydrate recognition domains. Proc. Natl. Acad. Sci. USA. 89, 118-122 (1992).

125. Ryan, M., McCarthy, L., Rappuoli, R., Mahon, B.P. \& Mills, K.H. Pertussis toxin potentiates Th1 and Th2 responses to co-injected antigen: adjuvant action is associated with enhanced regulatory cytokine production and expression of the co-stimulatory molecules B7-1, B7-2 and CD28. Int. Immunol. 10, 651-662 (1998).

126. Carbonetti, N.H. Pertussis toxin and adenylate cyclase toxin: key virulence factors of Bordetella pertussis and cell biology tools. Future Microbiol. 5, 455-469 (2010).

127. Shumilla, J.A. et al. Bordetella pertussis infection of primary human monocytes alters HLA-DR expression. Infect. Immun. 72, 1450-1462 (2004).

128. Martino, A., Volpe, E., Auricchio, G., Colizzi, V. \& Baldini, P.M. Influence of pertussis toxin on CD1a isoform expression in human dendritic cells. J. Clin. Immunol. 26, 153-159 (2006).

129. Schneider, O.D., Weiss, A.A. \& Miller, W.E. Pertussis toxin utilizes proximal components of the T-cell receptor complex to initiate signal transduction events in T cells. Infect. Immun. 75, 4040-4049 (2007).

130. Schneider, O.D., Weiss, A.A. \& Miller, W.E. Pertussis toxin signals through the TCR to initiate cross-desensitization of the chemokine receptor CXCR4. J. Immunol. 182, 5730-5739 (2009).

131. Carbonetti, N.H. et al. Suppression of serum antibody responses by pertussis toxin after respiratory tract colonization by Bordetella pertussis and identification of an immunodominant lipoprotein. Infect. Immun. 72 , 3350-3358 (2004).

132. Mielcarek, N. et al. Homologous and heterologous protection after single intranasal administration of live attenuated recombinant Bordetella pertussis. Nat. Biotechnol. 16, 454-457 (1998).

133. Andreasen, C. \& Carbonetti, N.H. Pertussis toxin inhibits early chemokine production to delay neutrophil recruitment in response to Bordetella pertussis respiratory tract infection in mice. Infect. Immun. 76, 5139-5148 (2008).

134. Ayala, V.I., Teijaro, J.R., Farber, D.L., Dorsey, S.G. \& Carbonetti, N.H. Bordetella pertussis infection exacerbates influenza virus infection through pertussis toxin-mediated suppression of innate immunity. PLoS One 6, e19016 (2011).

135. Hofstetter, H.H., Shive, C.L. \& Forsthuber, T.G. Pertussis toxin modulates the immune response to neuroantigens injected in incomplete Freund's adjuvant: induction of Th1 cells and experimental autoimmune encephalomyelitis in the presence of high frequencies of Th2 cells. J. Immunol. 169, 117-125 (2002).

136. Hou, W. et al. Pertussis toxin enhances Th1 responses by stimulation of dendritic cells. J. Immunol. 170, 1728-1736 (2003).

137. Chen, X., Howard, O.M. \& Oppenheim, J.J. Pertussis toxin by inducing IL-6 promotes the generation of IL-17-producing CD4 cells. J. Immunol. 178, 6123-6129 (2007). 
138. Cassan, C. et al. Pertussis toxin reduces the number of splenic Foxp3+ regulatory T cells. J. Immunol. 177, 1552-1560 (2006).

139. Chen, X. et al. Pertussis toxin as an adjuvant suppresses the number and function of CD4+CD25+ T regulatory cells. Eur. J. Immunol. 36, 671-680 (2006).

140. Weber, M.S. et al. Repetitive pertussis toxin promotes development of regulatory $T$ cells and prevents central nervous system autoimmune disease. PLoS One 5, e16009 (2010).

141. Everest, P. et al. Role of the Bordetella pertussis P.69/pertactin protein and the P.69/pertactin RGD motif in the adherence to and invasion of mammalian cells. Microbiology 142 (Pt 11), 3261-3268 (1996).

142. Charles, I.G. et al. Molecular cloning and characterization of protective outer membrane protein P.69 from Bordetella pertussis. Proc. Natl. Acad. Sci. USA. 86, 3554-3558 (1989).

143. Ruoslahti, E. RGD and other recognition sequences for integrins. Annu. Rev. Cell Dev. Biol. 12, 697-715 (1996).

144. Inatsuka, C.S. et al. Pertactin is required for Bordetella species to resist neutrophil-mediated clearance. Infect. Immun. 78, 2901-2909 (2010).

145. Roberts, M. et al. Construction and characterization of Bordetella pertussis mutants lacking the vir-regulated P.69 outer membrane protein. Mol. Microbiol. 5, 1393-1404 (1991).

146. Novotny, P., Chubb, A.P., Cownley, K. \& Charles, I.G. Biologic and protective properties of the $69-\mathrm{kDa}$ outer membrane protein of Bordetella pertussis: a novel formulation for an acellular pertussis vaccine. J. Infect. Dis. 164, 114-122 (1991).

147. Hijnen, M. et al. Epitope structure of the Bordetella pertussis protein P.69 pertactin, a major vaccine component and protective antigen. Infect. Immun. 72, 3716-3723 (2004).

148. Guermonprez, P. et al. The adenylate cyclase toxin of Bordetella pertussis binds to target cells via the alpha(M)beta(2) integrin (CD11b/ CD18). J. Exp. Med. 193, 1035-1044 (2001).

149. Eby, J.C., Gray, M.C., Mangan, A.R., Donato, G.M. \& Hewlett, E.L. Role of CD11b/CD18 in the process of intoxication by the Adenylate cyclase toxin of Bordetella pertussis. Infect. Immun. 80, 850-859 (2012).

150. Khelef, N. \& Guiso, N. Induction of macrophage apoptosis by Bordetella pertussis adenylate cyclase-hemolysin. FEMS Microbiol. Lett. 134, 27-32 (1995)

151. Gray, M.C. \& Hewlett, E.L. Cell cycle arrest induced by the bacterial adenylate cyclase toxins from Bacillus anthracis and Bordetella pertussis. Cell. Microbiol. 13, 123-134 (2011).

152. Kamanova, J. et al. Adenylate cyclase toxin subverts phagocyte function by RhoA inhibition and unproductive ruffling. J. Immunol. 181, 5587-5597 (2008)

153. Bagley, K.C., Abdelwahab, S.F., Tuskan, R.G., Fouts, T.R. \& Lewis, G.K. Pertussis toxin and the adenylate cyclase toxin from Bordetella pertussis activate human monocyte-derived dendritic cells and dominantly inhibit cytokine production through a cAMP-dependent pathway. J. Leukoc. Biol. 72, 962-969 (2002)

154. Hickey, F.B., Brereton, C.F. \& Mills, K.H. Adenylate cycalse toxin of Bordetella pertussis inhibits TLR-induced IRF-1 and IRF-8 activation and IL-12 production and enhances IL-10 through MAPK activation in dendritic cells. J. Leukoc. Biol. 84, 234-243 (2008).

155. Spensieri, F. et al. Bordetella pertussis inhibition of interleukin-12 (IL-12) p70 in human monocyte-derived dendritic cells blocks IL-12 p35 through adenylate cyclase toxin-dependent cyclic AMP induction. Infect. Immun. 74, 2831-2838 (2006).

156. Perkins, D.J., Gray, M.C., Hewlett, E.L. \& Vogel, S.N. Bordetella pertussis adenylate cyclase toxin (ACT) induces cyclooxygenase-2 (COX-2) in murine macrophages and is facilitated by ACT interaction with CD11b/CD18 (Mac-1). Mol. Microbiol. 66, 1003-1015 (2007).

157. Gray, M., Szabo, G., Otero, A.S., Gray, L. \& Hewlett, E. Distinct mechanisms for $\mathrm{K}+$ efflux, intoxication, and hemolysis by Bordetella pertussis AC toxin. J. Biol. Chem. 273, 18260-18267 (1998).

158. Cheung, G.Y. et al. Effect of different forms of adenylate cyclase toxin of Bordetella pertussis on protection afforded by an acellular pertussis vaccine in a murine model. Infect. Immun. 74, 6797-6805 (2006).

159. Betsou, F., Sebo, P. \& Guiso, N. The C-terminal domain is essential for protective activity of the Bordetella pertussis adenylate cyclasehemolysin. Infect. Immun. 63, 3309-3315 (1995).

160. Preston, A. et al. Genetic basis for lipopolysaccharide O-antigen biosynthesis in Bordetellae. Infect. Immun. 67, 3763-3767 (1999).
161. Harvill, E.T. et al. Multiple roles for Bordetella lipopolysaccharide molecules during respiratory tract infection. Infect. Immun. 68, 6720-6728 (2000).

162. Preston, A. \& Maskell, D. The molecular genetics and role in infection of lipopolysaccharide biosynthesis in the Bordetellae. J. Endotoxin Res. 7, 251-261 (2001)

163. Errea, A. et al. Mucosal innate response stimulation induced by lipopolysaccharide protects against Bordetella pertussis colonization. Med. Microbiol. Immunol. 199, 103-108 (2010).

164. Schaeffer, L.M., McCormack, F.X., Wu, H. \& Weiss, A.A. Bordetella pertussis lipopolysaccharide resists the bactericidal effects of pulmonary surfactant protein A. J. Immunol. 173, 1959-1965 (2004).

165. Loscher, C.E., Donnelly, S., McBennett, S., Lynch, M.A. \& Mills, K.H. Proinflammatory cytokines in the adverse systemic and neurologic effects associated with parenteral injection of a whole cell pertussis vaccine. Ann. NY Acad. Sci. 856, 274-277 (1998).

166. Loscher, C.E., Donnelly, S., Mills, K.H. \& Lynch, M.A. Interleukin-1 betadependent changes in the hippocampus following parenteral immunization with a whole cell pertussis vaccine. J. Neuroimmunol. 111, 68-76 (2000).

167. Donnelly, S., Loscher, C.E., Lynch, M.A. \& Mills, K.H. Whole-cell but not acellular pertussis vaccines induce convulsive activity in mice: evidence of a role for toxin-induced interleukin-1beta in a new murine model for analysis of neuronal side effects of vaccination. Infect. Immun. 69, 4217-4223 (2001).

168. Bannatyne, R.M. \& Jackowski, J. Protective effectiveness of an endotoxin-depleted pertussis vaccine. Vaccine 5, 268-269 (1987).

169. Cookson, B.T., Cho, H.L., Herwaldt, L.A. \& Goldman, W.E. Biological activities and chemical composition of purified tracheal cytotoxin of Bordetella pertussis. Infect. Immun. 57, 2223-2229 (1989).

170. Magalhaes, J.G. et al. Murine Nod1 but not its human orthologue mediates innate immune detection of tracheal cytotoxin. EMBO Rep. 6, 1201-1207 (2005).

171. Kaneko, T. et al. Monomeric and polymeric gram-negative peptidoglycan but not purified LPS stimulate the Drosophila IMD pathway. Immunity 20, 637-649 (2004)

172. Cookson, B.T., Tyler, A.N. \& Goldman, W.E. Primary structure of the peptidoglycan-derived tracheal cytotoxin of Bordetella pertussis. Biochemistry 28, 1744-1749 (1989).

173. Heiss, L.N., Flak, T.A., Lancaster, J.R. Jr., McDaniel, M.L. \& Goldman W.E. Nitric oxide mediates Bordetella pertussis tracheal cytotoxin damage to the respiratory epithelium. Infect. Agents Dis. 2, 173-177 (1993).

174. Flak, T.A., Heiss, L.N., Engle, J.T. \& Goldman, W.E. Synergistic epithelial responses to endotoxin and a naturally occurring muramyl peptide. Infect. Immun. 68, 1235-1242 (2000).

175. Cundell, D.R. et al. Effect of tracheal cytotoxin from Bordetella pertussis on human neutrophil function in vitro. Infect. Immun. 62, 639-643 (1994).

176. Cornelis, G.R. The type III secretion injectisome. Nat. Rev. Microbiol. 4, 811-825 (2006)

177. Kerr, J.R., Rigg, G.P., Matthews, R.C. \& Burnie, J.P. The Bpel locus encodes type III secretion machinery in Bordetella pertussis. Microb. Pathog. 27, 349-367 (1999).

178. Fauconnier, A. et al. Characterization of the type III secretion locus of Bordetella pertussis. Int. J. Med. Microbiol. 290, 693-705 (2001).

179. Mattoo, S., Yuk, M.H., Huang, L.L. \& Miller, J.F. Regulation of type III secretion in Bordetella. Mol. Microbiol. 52, 1201-1214 (2004).

180. Han, H.J., Kuwae, A., Abe, A., Arakawa, Y. \& Kamachi, K. Differential expression of type III effector BteA protein due to IS481 insertion in Bordetella pertussis. PLoS One 6, e17797 (2011).

181. Kuwae, A. et al. BopC is a novel type III effector secreted by Bordetella bronchiseptica and has a critical role in type III-dependent necrotic cell death. J. Biol. Chem. 281, 6589-6600 (2006).

182. Gaillard, M.E., Bottero, D., Castuma, C.E., Basile, L.A. \& Hozbor, D. Laboratory adaptation of Bordetella pertussis is associated with the loss of type three secretion system functionality. Infect. Immun. 79, 3677-3682 (2011).

183. Hallander, H.O., Advani, A., Donnelly, D., Gustafsson, L. \& Carlsson, R.M. Shifts of Bordetella pertussis variants in Sweden from 1970 to 2003 , during three periods marked by different vaccination programs. J. Clin. Microbiol. 43, 2856-2865 (2005). 


\section{REVIEW}

184. Mooi, F.R. et al. Bordetella pertussis strains with increased toxin production associated with pertussis resurgence. Emerg. Infect. Dis. $15,1206-1213$ (2009)

185. Jarnicki, A.G. et al. Attenuating regulatory T cell induction by TLR agonists through inhibition of p38 MAPK signaling in dendritic cells enhances their efficacy as vaccine adjuvants and cancer immunotherapeutics. J. Immunol. 180, 3797-3806 (2008).
186. Sugai, T. et al. A CpG-containing oligodeoxynucleotide as an efficient adjuvant counterbalancing the Th1/Th2 immune response in diphtheria-tetanus-pertussis vaccine. Vaccine $\mathbf{2 3}, 5450-5456$ (2005)

187. Marr, N. et al. Protective activity of the Bordetella pertussis BrkA autotransporter in the murine lung colonization model. Vaccine $\mathbf{2 6}$, 4306-4311 (2008). 